\title{
Assessing Gas-Hydrate Prospects on the North Slope of Alaska-Theoretical Considerations
}

Scientific Investigations Report 2008-5175 



\section{Assessing Gas-Hydrate Prospects on the North Slope of Alaska-Theoretical Considerations}

By Myung W. Lee, Timothy S. Collett, and Warren F. Agena

Scientific Investigations Report 2008-5175 


\title{
U.S. Department of the Interior DIRK KEMPTHORNE, Secretary
}

\author{
U.S. Geological Survey \\ Mark D. Myers, Director
}

U.S. Geological Survey, Reston, Virginia: 2008

For product and ordering information:

World Wide Web: http://www.usgs.gov/pubprod

Telephone: 1-888-ASK-USGS

For more information on the USGS - the Federal source for science about the Earth, its natural and living resources, natural hazards, and the environment:

World Wide Web: http://www.usgs.gov

Telephone: 1-888-ASK-USGS

Any use of trade, product, or firm names is for descriptive purposes only and does not imply endorsement by the U.S. Government.

Although this report is in the public domain, permission must be secured from the individual copyright owners to reproduce any copyrighted materials contained within this report.

Suggested citation:

Lee, M.W., Collett, T.S., and Agena, W.F., 2008, Assessing gas-hydrate prospects on the North Slope of AlaskaTheoretical considerations: U.S. Geological Survey, Scientific Investigations Report 2008-5175, 28 p. 


\section{Contents}

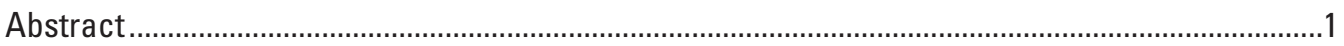

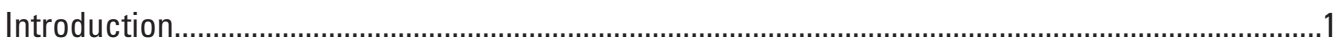

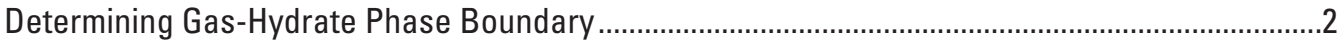

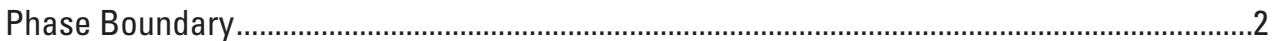

Various Relations Between Parameters..................................................................................

Measured Temperature Relative to Undisturbed Temperature ..................................................3

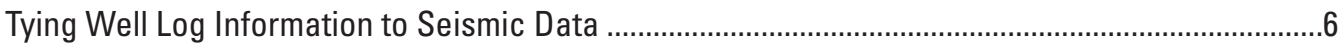

Determining Porosity and Ice/Gas-Hydrate Saturation ...............................................................

Least-Squares Fitting Method for Predicting P-Wave Velocity.................................................

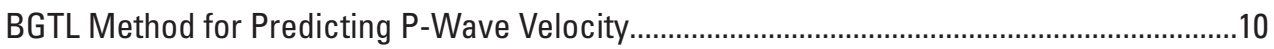

Combination of LSF and BGTL Methods for Predicting P-Wave Velocity ................................10

Differentiating Ice from Gas Hydrate in Permafrost ......................................................................11

Thermal Conductivity of Porous Medium ...............................................................................11

Estimating Thermal Conductivity Using Logs ...................................................................12

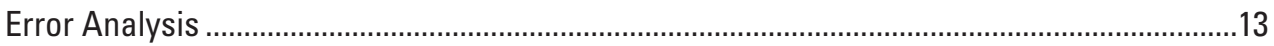

Example from Husky Oil Atigaru PT 1 Well ........................................................................14

Developing Acoustic Models for Reservoir and Seal ...............................................................16

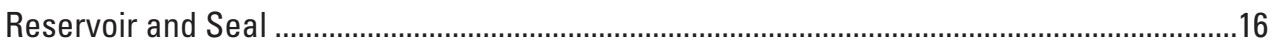

Elastic Velocities and Seismic Reflection Coefficient ..........................................................17

Developing a Method of Estimating Gas-Hydrate Saturation and Thickness ................................17

Summary and Conclusions.....................................................................................................

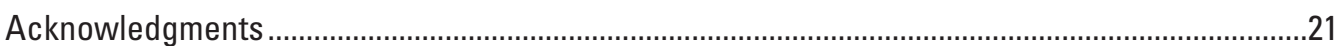

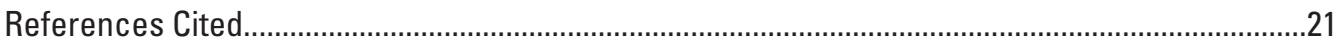

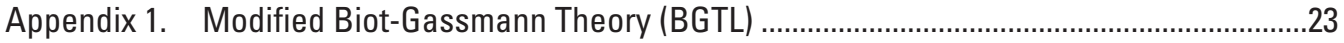

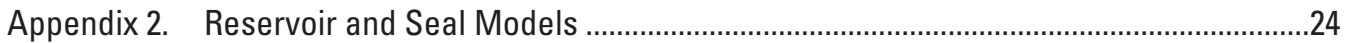

Appendix 3. Saturation and Thickness Interpretation Procedure ..............................................2

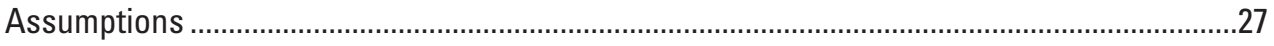

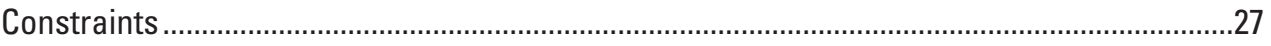

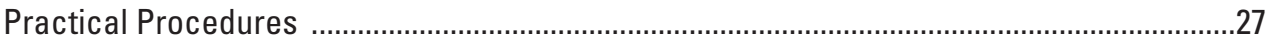




\section{Figures}

1-8. Graphs showing:

1. Methane-hydrate phase boundary and measured temperature................................

2. Relations between thermal gradient, permafrost, and phase boundary ....................5

3. Relations between thermal gradient and permafrost..............................................

4. Analysis of a resistivity log from Cape Halkett test well \#1, Alaska North Slope.......8

5. Various estimated porosities and compaction porosity at Cape Halkett test well \#1, Alaska North Slope .................................................................................

6. Relationships of resistivity, formation factor, and P-wave velocity at Colville River \#1 well, Alaska North Slope.

7. Comparison between measured P-wave velocity and P-wave velocity predicted from resistivity at Colville River \#1 well, Alaska North Slope

8. Comparison of P-wave velocity predicted from resistivity using various methods at Oberon \#1 well, Alaska North Slope..

9. 2-D seismic section overlain with a synthetic seismogram at Oberon \#1 well, Alaska North Slope.

10-19. Graphs showing:

10. Calculated thermal conductivity as a function of gas-hydrate/ice saturation..........13

11. Well logs for Husky Oil Atigaru PT 1 well, Alaska North Slope ...............................15

12. Gas-hydrate phase boundary, temperature, permafrost, and thermal conductivity at Husky Oil Atigaru PT 1 well, Alaska North Slope .................15

13. Reservoir and seal models derived for Arco Till \#1 well, Alaska North Slope ..........16

14. Calculated $\mathrm{P}$-wave velocity and reflection coefficient............................................18

15. Relations between reservoir thickness, gas-hydrate saturation, and seismic amplitude using a $60-\mathrm{Hz}$ (hertz) Ricker wavelet

16. Plots of various relations between apparent time thickness, amplitude, estimated saturation, and net pay thickness

17. Well log analysis at Arco Temptation \#1 well, Alaska North Slope, to derive reservoir and seal models.

18. Reservoir and seal models for Arco Temptation \#1 well, Alaska North Slope..........25

19. Reservoir and seal models for Arco Till \#1 well, Alaska North Slope........................26

\section{Tables}

1. Estimated top and bottom of gas-hydrate phase boundary (pure methane with 5 ppt salinity) with calculated thermal gradient inside the permafrost zone . .4

2. Elastic constants used in this study 


\title{
Assessing Gas-Hydrate Prospects on the North Slope of Alaska-Theoretical Considerations
}

\author{
By Myung W. Lee, Timothy S. Collett, and Warren F. Agena
}

\section{Abstract}

Gas-hydrate resource assessment on the Alaska North Slope using 3-D and 2-D seismic data involved six important steps: (1) determining the top and base of the gas-hydrate stability zone, (2) "tying" well log information to seismic data through synthetic seismograms, (3) differentiating ice from gas hydrate in the permafrost interval, (4) developing an acoustic model for the reservoir and seal, (5) developing a method to estimate gas-hydrate saturation and thickness from seismic attributes, and (6) assessing the potential gas-hydrate prospects from seismic data based on potential migration pathways, source, reservoir quality, and other relevant geological information. This report describes the first five steps in detail using well logs and provides theoretical backgrounds for resource assessments carried out by the U.S. Geological Survey.

Measured and predicted P-wave velocities enabled us to tie synthetic seismograms to the seismic data. The calculated gas-hydrate stability zone from subsurface wellbore temperature data enabled us to focus our effort on the most promising depth intervals in the seismic data. A typical reservoir in this area is characterized by the $\mathrm{P}$-wave velocity of $1.88 \mathrm{~km} / \mathrm{s}$, porosity of 42 percent, and clay volume content of 5 percent, whereas seal sediments encasing the reservoir are characterized by the P-wave velocity of $2.2 \mathrm{~km} / \mathrm{s}$, porosity of 32 percent, and clay volume content of 20 percent. Because the impedance of a reservoir without gas hydrate is less than that of the seal, a complex amplitude variation with respect to gas-hydrate saturation is predicted, namely polarity change, amplitude blanking, and high seismic amplitude (a bright spot). This amplitude variation with gas-hydrate saturation is the physical basis for the method used to quantify the resource potential of gas hydrates in this assessment.

\section{Introduction}

The gas-hydrate resource assessment on the Alaska North Slope (ANS) carried out in 2008 by the United States Geological Survey is based on seismic attributes derived from proprietary industry 3-D seismic data and publicly available 2-D seismic lines. In order to delineate gas-hydrate prospects and to estimate the potential resource for each prospect from the seismic data, a method of linking seismic attributes to the reservoir thickness and saturation is required. This report describes the details of this method applicable to the ANS.

The presence of gas hydrate in sediment pore spaces increases seismic velocities and the electrical resistivity of the formation, and these physical changes are detectable using various downhole well logs. Detecting and quantifying gas-hydrate-bearing sediments (GHBS) using seismic data, on the other hand, is not simple; detailed analyses, including calibration with well log information, are required to quantify the gas-hydrate response in seismic data. The basic concepts and interpretation, detection, and quantification methods were presented in Lee (2005) and Lee and others (in press), and an application of the concepts and methodology to real 3-D seismic data was presented by Inks and others (in press). This report is an extension of Lee (2005) and Lee and others (in press) and fills the gaps of previous investigations. This report describes five important steps in assessing gas-hydrate resources of the ANS: (1) determining the top and base of the gas-hydrate stability zone, (2) "tying" well log information to seismic data through synthetic seismograms, (3) differentiating ice from gas hydrate in the permafrost interval, (4) developing acoustic models for reservoir and seal, and (5) developing a method to estimate gas-hydrate saturation and thickness. Inks and others (in press) addressed the final step of the assessment, which is identifying the potential gas-hydrate prospects in terms of migration paths, source, reservoir quality, and other relevant geological information.

One important factor involved in the interpretation of seismic data for GHBS is determining where to look in the seismic sections for the potential prospects. This can be accomplished by calculating the distribution and thickness of the theoretical methane-hydrate phase boundary in any given setting. The extent of the gas-hydrate stability zone is then calculated using measured temperature data from various wells in and around the study area combined with theoretical gas-hydrate phase diagrams created using a computer program developed at the Colorado School of Mines, Golden, Colo. (Sloan and Koh, 2008).

In this study area, most P-wave velocity and bulk density logs were obtained below the gas-hydrate stability zone and, therefore, could not be used effectively to generate synthetic seismograms to tie time-domain surface-seismic data to depth. 
Fortunately, electrical resistivity and gamma ray logs were run in the shallow part of the sedimentary section. Therefore, the required P-wave velocities could be calculated using various methods to convert measured resistivity and porosity $\log$ values to $\mathrm{P}$-wave velocities. The method for predicting the P-wave velocity from resistivity using the modified BiotGassmann theory, referred to as the BGTL hereafter, is given by Lee (2005) and Lee and Collett (2008). For this study, a least-squares fitting method (for example, Rudman and others, 1975 ) is incorporated into the BGTL method and various combinations of methods are attempted to produce the best possible P-wave velocity logs.

Because the permafrost and gas-hydrate stability zones can overlap, gas hydrates are often commingled with ice. Because elastic and electrical properties of gas hydrate and ice are similar, velocity and resistivity logs are not effective for differentiating ice from gas hydrate. On the other hand, the thermal conductivities of ice and gas hydrate are markedly different (Sloan and Koh, 2008), thus providing the possibility to distinguish the two.

The properties of the reservoir and seal are important for building the relation between the seismic amplitudes, thicknesses, and saturations used as the basis of the interpretational method proposed by Lee and others (in press). Three reservoir and seal models are investigated, and the difference between different models in estimating gas-hydrate saturation and thickness is assessed.

This report includes three appendixes. Appendix 1 briefly describes the fundamentals of the BGTL, appendix 2 presents two reservoir and seal models derived from depths near 2,400 ft by accounting for the effect of pore saturants on the P-wave velocity, and appendix 3 describes the detailed procedure of the complex thin-bed analysis method used to estimate gas-hydrate saturations and thicknesses of reservoirs.

\section{Determining Gas-Hydrate Phase Boundary}

\section{Phase Boundary}

Gas hydrate exists only within the gas-hydrate stability zone (GHSZ), so determining the depth of a phase boundary is an important step in assessing the gas-hydrate potential of the ANS. The GHSZ is determined from the temperature, pressure, water salinity, and gas composition. The purpose of this section is (1) to explain how to determine the GHSZ using available high-resolution temperature data and (2) to derive a workable relation between the depth of the base of the GHSZ and that of the base of the permafrost, which can be used for wells without temperature data.

When borehole temperature data are available, the gas-hydrate phase boundary (GHPB) can be easily found by plotting the temperature as a function of depth and superimposing the theoretical GHPB on it. The resulting intersection points between the temperature and theoretical GHPB curves correspond to the top and base of the GHSZ. For this study, the theoretical GHPB curve was derived using a computer program called CSMHYD developed at the Colorado School Mines, Golden, Colo. (Sloan and Koh, 2008). The theoretical GHPB curve used for this study was generated assuming 100-percent methane gas and water salinity of 5 ppt.

An example from one of the ANS wells, the West Sak River \#14 well, is shown in figure 1. The temperature curve is indicated by a red line, and the theoretical GHOB curve is indicated by a green line. The intersection points for these curves occur at $214.8 \mathrm{~m}$ and $741 \mathrm{~m}$ and correspond to the top and base of the GHSZ, respectively. The base of permafrost by definition occurs at $0^{\circ} \mathrm{C}$, but the temperature at the base of icebearing permafrost is variable depending on the shale content and water salinity and typically varies from $-4.5^{\circ} \mathrm{C}$ to $-0.5^{\circ} \mathrm{C}$ (Collett and others, 1988). For the West Sak River \#14 well,
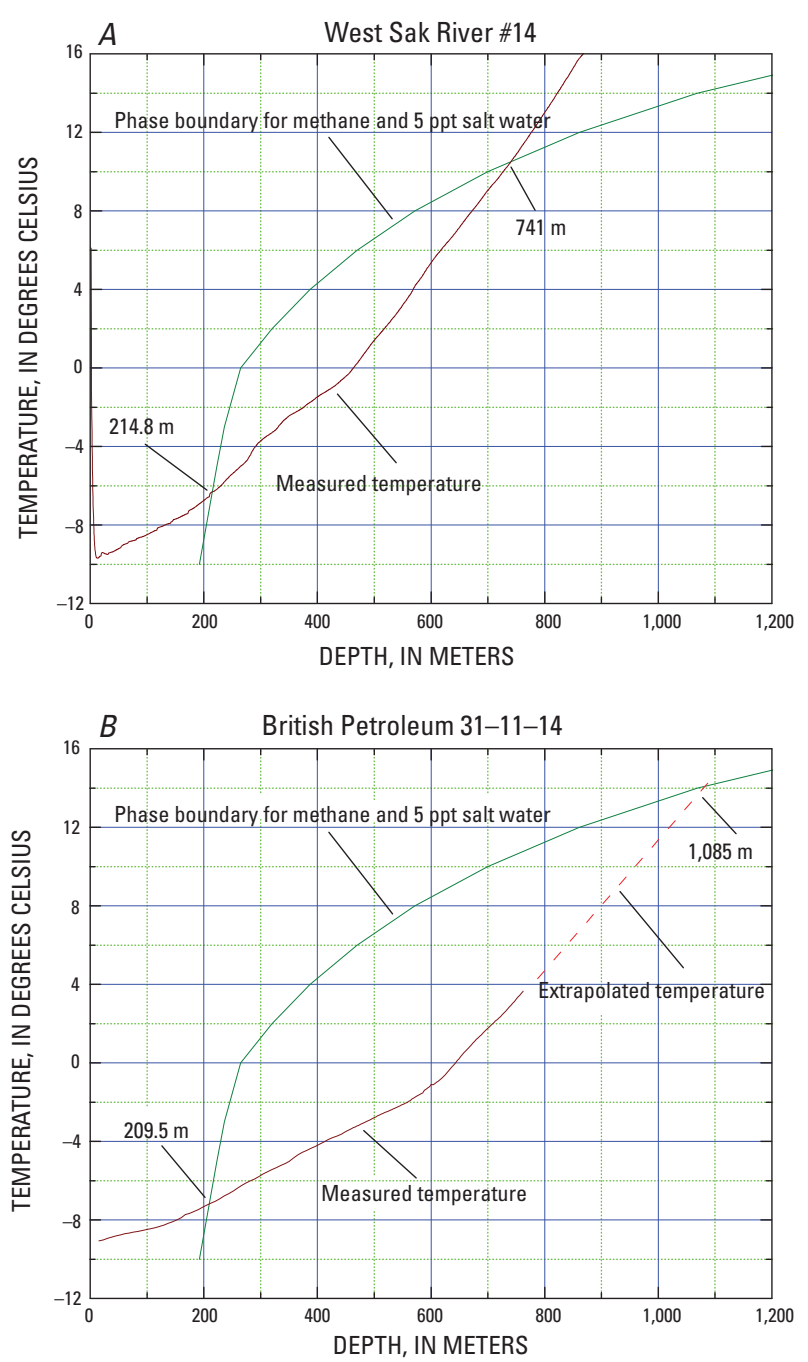

Figure 1. Methane-hydrate phase boundary and measured temperature. A. West Sak River \#14 well, Alaska North Slope. B. British Petroleum 31-11-14 well, Alaska North Slope. 
$-0.5^{\circ} \mathrm{C}$ occurs at a depth of approximately $450 \mathrm{~m}$. Therefore, ice and gas hydrate can coexist at depths from approximately $214 \mathrm{~m}$ to $450 \mathrm{~m}$ in the West Sak River \#14 well.

When the temperature data were not acquired deep enough to intersect the phase boundary curve, the in-situ temperatures are extrapolated as shown by the dashed line in figure $1 B$ for the British Petroleum 31-11-14 well. The extrapolation of temperature is based on the assumption that the thermal gradient below the permafrost is nearly constant. This assumption appears to be valid for most of the wells investigated in ANS. Table 1 shows depths of the top and base of the phase boundaries determined from the temperature data in the ANS. The GHSZ determined using extrapolated temperatures are shown inside the shaded region in table 1. All borehole temperature data used in this investigation are from Clow and Lachenbruch (1998).

\section{Various Relations Between Parameters}

Figure $2 A$ shows the depth of the top and base of the GHSZ as a function of the depth to $0^{\circ} \mathrm{C}$ and segregated by region for data shown in table 1 . The closed symbols indicate the top of the GHSZ, whereas the open symbols indicate the base of the GHSZ. The phase boundaries for the eastern and western regions behave systematically with respect to the depth to $0^{\circ} \mathrm{C}$, but the relation breaks down for the front range data, where the surface temperatures vary wildly. Excluding the front range data, the relations are given by the following equations:

$$
\begin{aligned}
& D_{B G H S Z}=2 \mathrm{D}_{B P F}-200 \\
& D_{T G H S Z}=-D_{B P F} / 6+300
\end{aligned}
$$

where

$$
D \text { is depth in meters }
$$

and

BGHSZ, TGHSZ, and BPF refer to the base of the GHSZ, to the top of the GHSZ, and to the base of permafrost $\left(0^{\circ} \mathrm{C}\right)$ respectively.

Figure $2 B$ shows the relation between the thermal gradient below the permafrost and the base of the GHSZ. Ignoring the data from the front range, the relation is given by:

$$
\log _{10} D_{B G H S Z}=-1.15 \log _{10} G+1.0
$$

where

$G$ is the thermal gradient in ${ }^{\circ} \mathrm{C} / \mathrm{m}$.

The thermal gradient for the eastern region is about twice that for the western region. Also note that the thickness of the permafrost for the eastern region (fig. $2 A$ ) is about twice that of the western region.

Although it is impossible to determine the location of $0^{\circ} \mathrm{C}$ using only a resistivity log, it is possible to determine the base of ice-bearing permafrost in certain cases. As indicated in Osterkamp and Payne (1981), determining the base of ice-bearing strata in coarse-grained ice-rich sediments in the eastern National Petroleum Reserve in Alaska (NPRA) is easier, but for the finer-grained sediments generally found in the western NPRA, it is difficult to determine the base of icebearing permafrost, partly caused by freezing-point depression in the finer-grained sediment. For example, in Husky Oil Atigaru PT 1 well, the base of ice-bearing permafrost is estimated to be at the depth of about $365 \mathrm{~m}$ on the basis of the presence of high resistivities overlying low resistivities on the resistivity $\log$. However, the depth to $0^{\circ} \mathrm{C}$ from the temperature $\log$ is at $400 \mathrm{~m}$. Therefore, using equation 1 to determine the base of the GHSZ requires caution, particularly in the western region.

Equation 1 is used to determine the base of GHSZ where no temperature data are available. The base of ice-bearing permafrost is determined from the resistivity log and the depth to $0^{\circ} \mathrm{C}$ is estimated based on the character of the resistivity log. Using equation 1, the base of the GHSZ at the Arco Till \#1 well and the Conoco-Phillips Spark \#1 well are determined to be 2,150 ft and 1,200 ft, respectively. These estimates are compared to those determined from temperature data.

The relation between the thermal gradients in the gas hydrate and permafrost is shown in figure 3 . Let the average thermal gradient from the surface to the depth of $0^{\circ} \mathrm{C}$ be $G_{i c e}$ and the average thermal gradient from the depth of $0^{\circ} \mathrm{C}$ to the base of GHSZ be $G_{h y d}$. Figure $3 A$ indicates that to a firstorder approximation, the ratio of $G_{h y d} / G_{i c e}$ linearly decreases with respect to $G_{i c e}$ or the ratio increases as the depth to $0^{\circ} \mathrm{C}$ increases (fig. $3 B$ ). Because the thermal conductivity is inversely proportional to the thermal gradient under the assumption of constant heat flow (in other words, there are no heat sources or sinks), figure 3 indicates that the effect of ice is much reduced in the western region compared to the eastern region. The smaller ratio of $G_{h y d} / G_{i c e}$ in the western region is possibly caused by the thin permafrost with less ice content and shalier or finer-grained lithology. Note that $G_{i c e}$ (fig. 2B) and the ratio $G_{h y d} / G_{i c e}$ (fig. 3) in the eastern region do not overlap those of the western region.

\section{Measured Temperature Relative to Undisturbed Temperature}

Drilling a well disturbs the in-situ temperature. The undisturbed temperature can be estimated from the measured temperature by assuming that drilling acted as a constant heat source of duration $s$. Lachenbruch and Brewer (1959) showed that the successive temperature measurement at a given depth at time $t$ since the completion of disturbance is given by:

$$
\theta(\tau) \cong A \ln (1+1 / \tau)+\theta_{\infty}
$$

where

$\tau=t / s$

$A$ is a constant with the dimension of temperature, and

$\theta_{\infty}$ is the undisturbed pre-drilling temperature.

Lachenbruch and others (1988) showed that the observed temperatures range from about $0.1{ }^{\circ} \mathrm{C}$ to $0.9^{\circ} \mathrm{C}$ 
Table 1. Estimated top and bottom of gas-hydrate phase boundary (pure methane with 5 ppt salinity) with calculated thermal gradient inside the permafrost zone.

[It is assumed that $0^{\circ} \mathrm{C}$ corresponds to the base of the permafrost. Numbers inside the shaded regions are depths estimated from the extrapolated temperatures at each well. Gas-hydrate phase boundary for wells with * are not used in the study. EV, elevation; KB, Kelly bushing; DTZ, depth to $0^{\circ} \mathrm{C}$; TPB, depth to the top of gas-hydrate phase boundary; $\mathrm{BPB}$, depth to the bottom of gas-hydrate phase boundary; TG, thermal gradient; RG, region in Alaska North Slope; E, eastern region; F, front range; W, western region]

\begin{tabular}{|c|c|c|c|c|c|c|c|c|}
\hline $\begin{array}{c}\text { Common } \\
\text { well } \\
\text { name }\end{array}$ & API & $\begin{array}{c}\text { EV } \\
\text { (m) }\end{array}$ & $\begin{array}{l}\text { KB } \\
\text { (m) }\end{array}$ & $\begin{array}{l}\text { DTZ } \\
\text { (m) }\end{array}$ & $\begin{array}{l}\text { TPB } \\
(\mathrm{m})\end{array}$ & $\begin{array}{c}\text { BPB } \\
(\mathrm{m})\end{array}$ & $\begin{array}{c}\mathrm{TG} \\
{ }^{\circ} \mathrm{C} / \mathrm{m}\end{array}$ & RG \\
\hline East bay State \#1 & 50029201330000 & 5.20 & 15.55 & 620.0 & 210.6 & 1130.0 & 0.0177 & $\mathrm{E}$ \\
\hline AT Highland ST 1 & 50029201990000 & 16.00 & 21.03 & 575.0 & 210.0 & 908.0 & 0.0191 & $\mathrm{E}$ \\
\hline AT NW Eileen ST 1 & 50029200130000 & 21.00 & 22.86 & 530.0 & 207.0 & 860.0 & 0.0208 & $\mathrm{E}$ \\
\hline Put River 33-12-13 & 50029200470000 & 9.0 & 14.63 & 650.0 & 205.5 & 1180.0 & 0.0169 & $\mathrm{E}$ \\
\hline Put River J-3: 04-11-13 & 50029200250000 & 11.00 & 17.37 & 635.0 & 208.5 & 1063.0 & 0.0173 & $\mathrm{E}$ \\
\hline Put River 19-10-5 & 50029200350000 & 11.00 & 17.00 & 585.0 & 218.0 & 1048.0 & 0.0188 & $\mathrm{E}$ \\
\hline Put River 23-11-13 & 50029200540000 & 10.00 & 17.69 & 540.0 & 209.7 & 1065.0 & 0.0204 & $\mathrm{E}$ \\
\hline North Prudhoe Bay State 1 & 50029200490000 & 2.0 & 13.41 & 596.0 & 206.0 & 1057.0 & 0.0185 & $\mathrm{E}$ \\
\hline Put River N-1: 08-11-13 & 50029200790000 & 8.00 & 18.90 & 615.0 & 209.3 & 1019.0 & 0.0179 & $\mathrm{E}$ \\
\hline Put River 31-11-14 & 50029200590000 & 10.00 & 18.29 & 640.0 & 209.5 & 1085.0 & 0.0172 & $\mathrm{E}$ \\
\hline *Put River F-2-11-11-13 & 50029200840000 & 6.00 & 17.37 & 630.0 & 216.2 & 1048.0 & 0.0175 & $\mathrm{E}$ \\
\hline *Put River F-3-12-11-13 & 50029200850000 & 6.00 & 17.07 & 630.0 & 229.2 & 1105.0 & 0.0175 & $\mathrm{E}$ \\
\hline *Sag delta 31-10-16 & 50029200300000 & 14.00 & 19.51 & 590.0 & 223.7 & 1010.0 & 0.0179 & $\mathrm{E}$ \\
\hline West Sak 11 & 50029202750000 & 19.00 & 25.30 & 465.0 & 216.2 & 746.5 & 0.0237 & $\mathrm{E}$ \\
\hline So West Sak 14 & 50029204190000 & 40.00 & 40.54 & 465.0 & 214.8 & 741.0 & 0.0206 & $\mathrm{E}$ \\
\hline West Sak 16 & 50029205410000 & 18.00 & 18.59 & 535.0 & 211.6 & 845.0 & 0.02 & $\mathrm{E}$ \\
\hline So West Sak 17 & 50029205420000 & 18.00 & 18.29 & 550.0 & 210.0 & 850.0 & 0.02 & $\mathrm{E}$ \\
\hline AR West Sak River St 1 & 50029200900000 & 18.00 & 26.52 & 550.0 & 211.6 & 800.0 & & $\mathrm{E}$ \\
\hline US Awuna \#1 & 50155200010000 & 336.0 & 344.12 & 236.0 & 263.7 & 467.8 & & $\mathrm{~F}$ \\
\hline MO Echooka 1 & 50223200080000 & 200.0 & 206.15 & 265.0 & 263.2 & 787.0 & & $\mathrm{~F}$ \\
\hline US Koluktak 1 & 50119200010000 & 56.00 & 62.48 & 280.0 & 257.0 & 540.0 & & $\mathrm{~F}$ \\
\hline *US Lisburne \#1 & 50137200030000 & 559.0 & 567.54 & 264.0 & 264.0 & 783.0 & & $\mathrm{~F}$ \\
\hline FO Lupine 1 & 50223200110000 & 520.0 & 530.0 & 220.0 & 337.0 & 660.0 & & $\mathrm{~F}$ \\
\hline BP Kuparuk K 1 & 50287100180000 & 189.0 & 192.63 & 265.0 & 262.0 & 595.0 & & $\mathrm{~F}$ \\
\hline *US Seabee 1 & 50287200070000 & 89.00 & 98.15 & 300.0 & 257.7 & 1070.0 & & $\mathrm{~F}$ \\
\hline HU Atigaru PT 1 & 50103200080000 & 2.1 & 7.62 & 400.0 & 216.6 & 541.0 & 0.0275 & W \\
\hline HU Drew Point 1 & 50279200020000 & 3.00 & 10.67 & 320.0 & 232.0 & 460.0 & 0.03438 & $\mathrm{~W}$ \\
\hline US E Simpson 1 & 50279200050000 & 3.70 & 9.17 & 360.0 & 228.0 & 556.0 & 0.03056 & $\mathrm{~W}$ \\
\hline HU E Teshekpuk 1 & 50103200060000 & 4.9 & 9.45 & 250.0 & 0.0 & 0.0 & 0.044 & $\mathrm{~W}$ \\
\hline HU West Fish Creek 1 & 50103200090000 & 26.5 & 33.53 & 260.0 & 0.0 & 0.0 & 0.0423 & W \\
\hline HU Ikpikpuk 1 & 50279200040000 & 9.1 & 15.85 & 350.0 & 242.6 & 652.0 & 0.0333 & $\mathrm{~W}$ \\
\hline US J W Dalton & 50279200060000 & 4.60 & 11.89 & 400.0 & 213.3 & 604.0 & 0.0275 & W \\
\hline HU Kugrua \#1 & 50163200020000 & 20.00 & 25.91 & 270.0 & 258.7 & 389.5 & 0.0333 & W \\
\hline US Kuyanak \#1 & 50163200030000 & 3.00 & 8.53 & 320.0 & 232.7 & 500.0 & 0.0344 & W \\
\hline US North Inigok 1 & 50103200170000 & 46.00 & 50.60 & 275.0 & 257.6 & 380.0 & 0.0431 & $\mathrm{~W}$ \\
\hline US North Kalikpik 1 & 50103200110000 & 4.60 & 12.19 & 210.0 & 0.0 & 0.0 & 0.0524 & W \\
\hline US Peard \#1 & 50301200020000 & 23.00 & 31.39 & 300.0 & 248.0 & 557.0 & 0.0367 & W \\
\hline
\end{tabular}


Table 1. Estimated top and bottom of gas-hydrate phase boundary (pure methane with 5 ppt salinity) with calculated thermal gradient inside the permafrost zone. - Continued

[It is assumed that $0^{\circ} \mathrm{C}$ corresponds to the base of the permafrost. Numbers inside the shaded regions are depths estimated from the extrapolated temperatures at each well. Gas-hydrate phase boundary for wells with * are not used in the study. EV, elevation; KB, Kelly bushing; DTZ, depth to $0^{\circ} \mathrm{C}$; TPB, depth to the top of gas-hydrate phase boundary; $\mathrm{BPB}$, depth to the bottom of gas-hydrate phase boundary; TG, thermal gradient; RG, region in Alaska North Slope; E, eastern region; F, front range; W, western region]

\begin{tabular}{|c|c|c|c|c|c|c|c|c|}
\hline $\begin{array}{c}\text { Common } \\
\text { well } \\
\text { name }\end{array}$ & API & $\begin{array}{l}\text { EV } \\
\text { (m) }\end{array}$ & $\begin{array}{l}\text { KB } \\
\text { (m) }\end{array}$ & $\begin{array}{l}\text { DTZ } \\
\text { (m) }\end{array}$ & $\begin{array}{l}\text { TPB } \\
\text { (m) }\end{array}$ & $\begin{array}{c}\text { BPB } \\
(\mathrm{m})\end{array}$ & $\begin{array}{c}\mathrm{TG} \\
{ }^{\circ} \mathrm{C} / \mathrm{m}\end{array}$ & RG \\
\hline US So Meade \#1 & 50163200010000 & 10.70 & 18.29 & 200.0 & 0.0 & 0.0 & 0.055 & $\mathrm{~W}$ \\
\hline US So Barrow \#3 & 50023100110000 & 9.00 & 13.41 & 380.0 & 232.0 & 578.0 & 0.029 & $\mathrm{~W}$ \\
\hline HU S Harrison Bay 1 & 50103200070000 & 7.6 & 13.72 & 380.0 & 224.7 & 530.0 & 0.029 & $\mathrm{~W}$ \\
\hline US Tunalik \#1 & 50301200010000 & 24.00 & 33.53 & 270.0 & 257.7 & 320.0 & 0.0407 & $\mathrm{~W}$ \\
\hline US Tulageak 1 & 50023200180000 & 3.0 & 5.18 & 290.0 & 249.5 & 387.7 & 0.0379 & $\mathrm{~W}$ \\
\hline US West Dease \#1 & 50023200140000 & 2.0 & 7.32 & 270.0 & 256.5 & 352.0 & 0.0407 & W \\
\hline
\end{tabular}
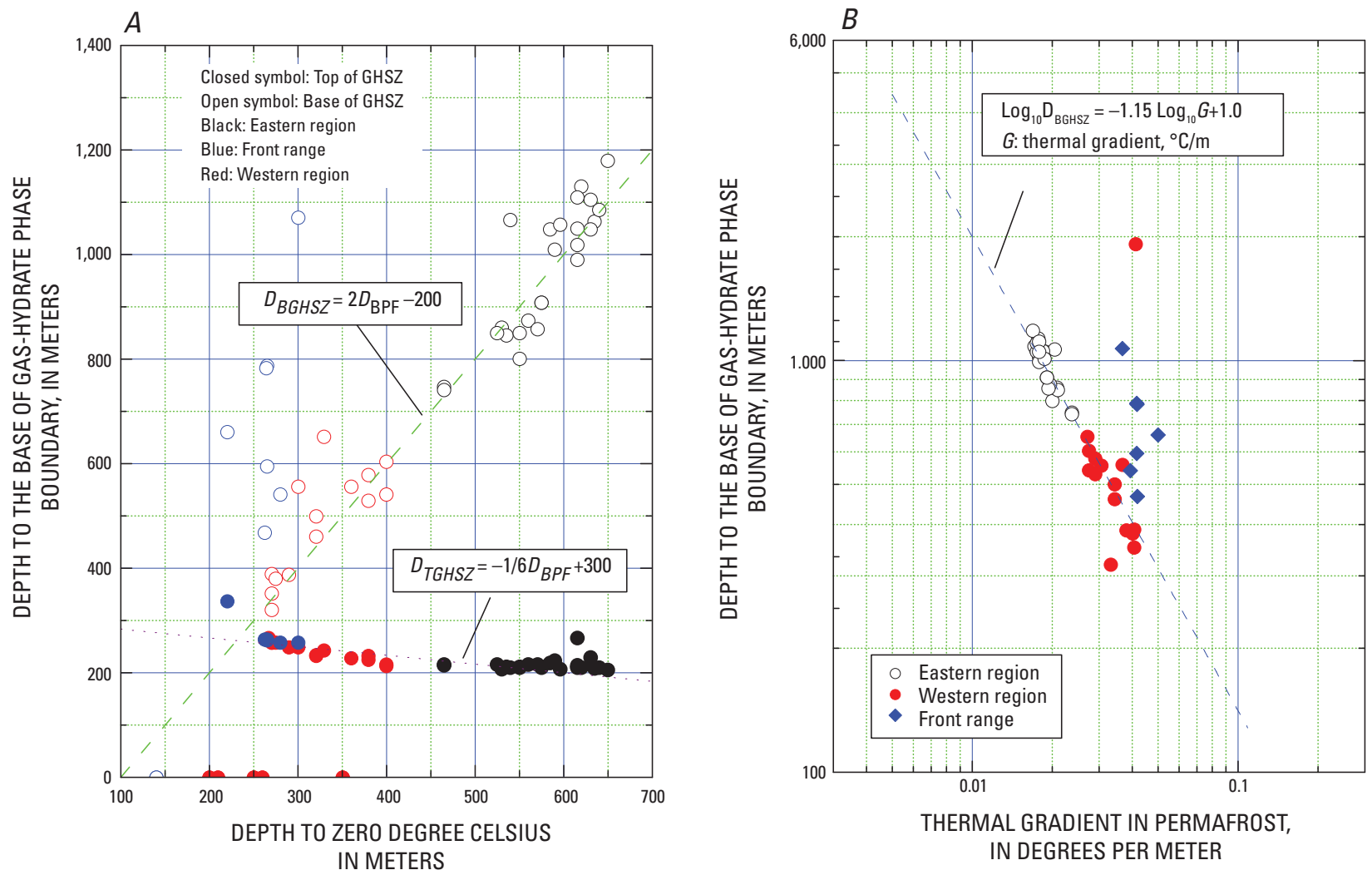

Figure 2. Relations between thermal gradient, permafrost, and phase boundary. $\boldsymbol{A}$. Relation between depth to $0^{\circ} \mathrm{C}$ with respect to top of the gas-hydrate stability zone (TGHSZ) and base of the gas-hydrate stability zone (BGHSZ). BPF, base of permafrost; GHSZ, gas-hydrate stability zone. B. Relation between thermal gradient in the permafrost interval and depth to the base of the gas-hydrate phase boundary. 

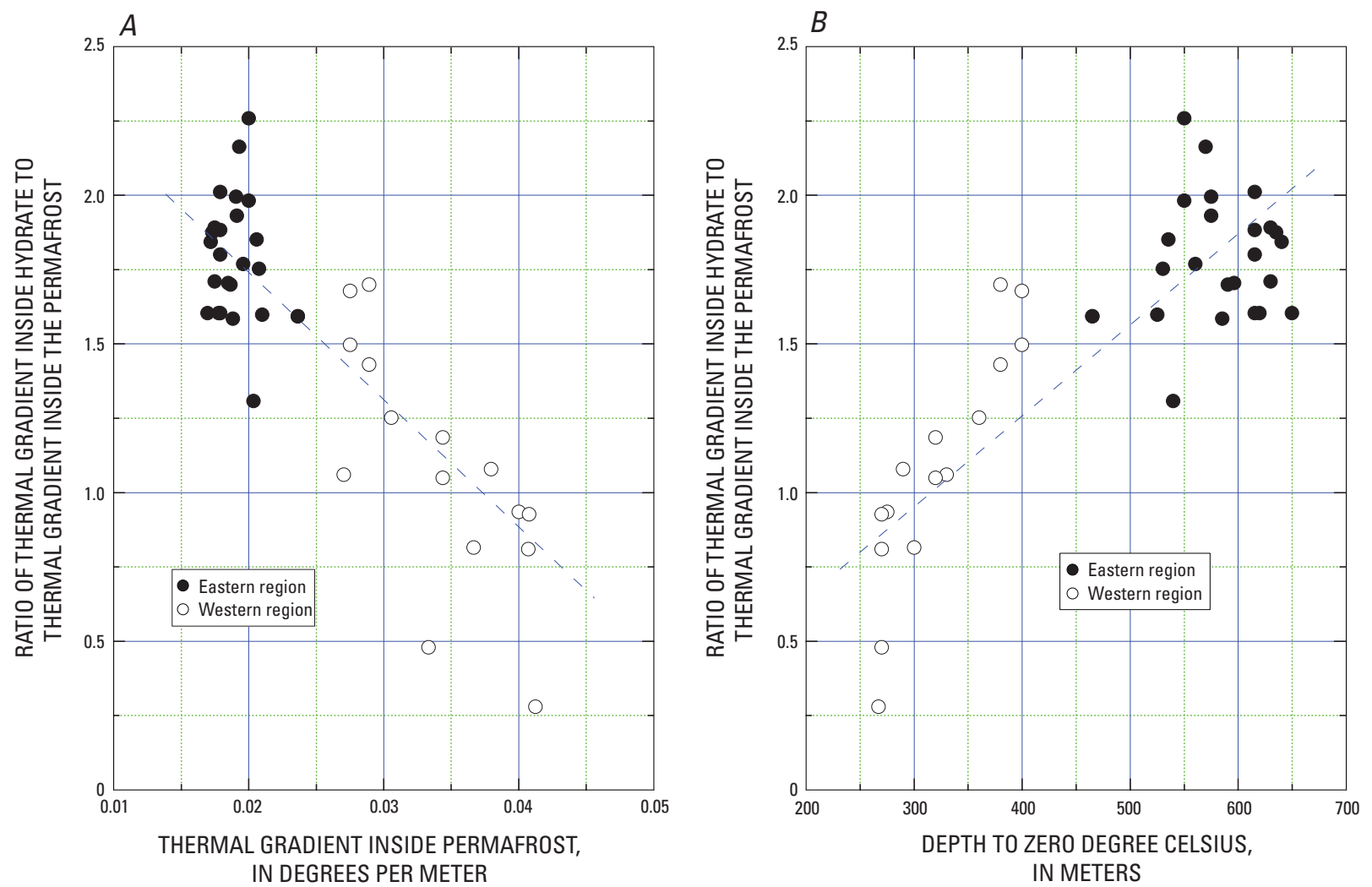

Figure 3. Relations between thermal gradient and permafrost $\boldsymbol{A}$. Relation between thermal gradient inside permafrost and ratio of the gradient inside the gas hydrate to the gradient inside the permafrost. $\boldsymbol{B}$. Relation between depth to $0^{\circ} \mathrm{C}$ and ratio of the gradient inside the gas hydrate to the gradient inside the permafrost.

above the undisturbed temperature. In this study, we did not incorporate the difference between the measured temperature and undisturbed temperature. If undisturbed temperatures calculated by Lachenbruch and others (1988) were used, the depth of GHSZ differs by about $0-30 \mathrm{~m}$. Consequently the top of the GHSZ becomes about 0-10 m shallower, and the base of GHSZ becomes about 0-30 m deeper. Furthermore, the depth of $0^{\circ} \mathrm{C}$ used in this study is different from those estimated by Lachenbruch and others (1988). For example, the depth to $0^{\circ} \mathrm{C}$ at the Husky Oil Atigaru PT 1 well is $400 \mathrm{~m}$ in this study, whereas it is $405 \mathrm{~m}$ according to Lachenbruch and others (1988). For most wells in our study area, the dimensionless time $\tau$ is greater than 20 , thus it is deemed that the effect of the difference between the measured and undisturbed temperature on the gas-hydrate assessment is insignificant. Therefore, wells with highly unequilibrated temperatures such as British Petroleum 31-10-16 and Put River F-4-01-11-13 have been ignored in determining the gas-hydrate phase boundary.

\section{Tying Well Log Information to Seismic Data}

Most wells in the study area do not have sonic and density logs for the shallow parts of the well where most of the gas hydrate is present, and some have no sonic log at all. Therefore, it is necessary to predict P-wave velocities to tie the well information to the seismic data. Fortunately, most wells have resistivity and gamma ray logs over the entire wellbore. Pratson and others (2003) proposed a method of predicting porosity and $\mathrm{P}$-wave velocities using only the gamma ray $\log$. Their method is based on a sequence of established petrophysical formulations and applied to unconsolidated sediments at the Amazon Fan. This method is primarily built on predicted porosity using a model by Marion and others (1992). The porosity and clay volume data in the assessment study area do not accurately follow the Marion model; therefore, the proposed method by Pratson and others (2003) was not considered in this report. 
The P-wave velocities can be predicted from resistivity logs using a least-squares fitting (LSF) method or using the BGTL (appendix 1) by explicitly inserting the pore saturants in the velocity equation. Lee and Collett (2008) preferred to use the BGTL method as opposed to the LSF method for gas-hydrate-bearing sediments. The BGTL method requires accurate porosity information, whereas the LSF only requires resistivity logs. For the LSF method, however, if the resistivity of the connate water varies with depth, the formation factor $(F F)$ rather than electrical resistivity should be used to predict the velocities. But porosity is also required to estimate formation factor. Therefore, both the BGTL and LSF methods require accurate porosities in order to predict accurate velocities.

\section{Determining Porosity and Ice/Gas-Hydrate Saturation}

As mentioned previously, whether the BGTL or LSF method is used to predict P-wave velocity, accurate porosity information is required. Unfortunately, most of the porosity logs in our study area were measured at depths below the intervals of interest. An approximate porosity was estimated from resistivity logs using the quick-look method by Collett (2000) incorporating a compaction curve for the assessment area (Lee, 2005). The quick-look method uses an assumed base-line resistivity $\left(R_{o}\right)$ to estimate the water saturation. The water saturation $\left(S_{w}\right)$ can be estimated by:

where

$$
S_{w}=\left(\frac{R_{o}}{R_{t}}\right)^{1 / n}
$$

$n$ is about 2.

In full Archie analysis, the water saturation is given by:

$$
S_{w}=\left(\frac{a R_{w}}{\phi^{m} R_{t}}\right)^{1 / n}
$$

where

$R_{t}$ is the measured resistivity, and

$a$ and $m$ are Archie parameters. $R_{t}$ is equal to $R_{o}$ when the pore is saturated with water.

The base-line resistivity $R_{o}$ in equation 5 can be written using equation 6 as:

$$
R_{o}=\frac{a R_{w}}{\phi^{m}}=\frac{R_{a}}{\phi^{m}}
$$

where

$R_{a}\left(R_{a}=a R_{w}\right)$ is the apparent resistivity of connate water.

When using the full Archie analysis, $R_{o}$ is computed using $a, m, R_{w}$, and $\phi$, whereas $R_{o}$ is determined graphically in the quick-look method. Equation 7 indicates that the apparent resistivity $R_{a}$ can be calculated if $R_{o}$, porosity and the Archie parameter $m$ are known. From equation 7, formation factor $(F F)$ is given by:

$$
F F=\frac{R_{t}}{R_{w}}=\frac{a R_{t}}{R_{o} \phi^{m}}
$$

The porosity of water-saturated sediment can be calculated as:

$$
\phi=\left(\frac{R_{o} \phi^{m}}{R_{t}}\right)^{1 / m}=\left(\frac{R_{o}}{R_{t}}\right)^{1 / m} \phi
$$

Equation 9, however, is valid only if $R_{o}=R_{t}$ or $S_{w}=1$ (100-percent water saturation). If equation 9 is used to calculate porosity using the measured resistivity $\left(R_{t}\right)$, the calculated porosity is less than the input porosity if $S_{w}$ is not equal to one. Equation 9 implies that, if $R_{o}$ can be adjusted in a certain way, porosities can be estimated at depths where the $S_{w}$ is not equal to one. These porosities can be used in predicting P-wave velocities, as will be shown later.

Figure 4 shows an example of the ice/gas-hydrate saturation estimated using the quick-look method for the Cape Halkett test well \#1, ANS. The green line in figure $4 A$ is the assumed $R_{o}$ that was used as input. Figure $4 B$ shows the estimated ice/gas-hydrate/hydrocarbon saturation that resulted from the quick-look method using $n=2$.

Figure 5 shows the density porosity at this well. Because the density porosity was measured for depths deeper than $2,340 \mathrm{ft}$, a local compaction curve (Lee, 2005) was used to determine the porosity for depths less than 2,340 ft. The compaction porosity is given by:

$$
\phi_{c}=0.532 e^{-\left(d+d_{\text {shift }}\right) / 6442}+\phi_{\text {bias }}
$$

where

$d$ is depth in feet, $d_{\text {shift }}$ is a depth shift in feet to accommodate the tectonic effect such as uplifts, and

$\phi_{\text {bias }}$ is the constant porosity to fit the compaction curve to the local porosity variation.

The compaction porosity in figure 5 is derived using equation 10 with $\phi_{\text {bias }}=-0.04$ and $d_{\text {shift }}=0$.

Porosities were estimated using equation 9 with $m=1.7$, $R_{o}$ that is shown as a green line in figure $4 A$, and porosity given as a red line in figure 5. The estimated porosities are shown as a blue line in figure 5. As expected, the calculated porosities using equation 9 are less than the input porosities at shallow depths where significant ice/gas-hydrate saturations are estimated (fig. 4B). To estimate more reasonable porosity at shallow depths, a new $R_{o}$ is assumed and shown as a red line in figure $4 A$. The porosity estimated using this $R_{o}$ is shown as a green line in figure 5 and appears to be reasonable for all depths. The logic behind this method of estimating porosity is based on the assumption that the resistivity variation is primarily caused by variable $R_{w}$ or $R_{a}$ instead of nonconducting saturants in the pore. Because the choice of $R_{o}$ used to derive the porosity above is not based on physics, the estimated porosity may or may not be reasonable. As $S_{w}$ approaches 1 , or $R_{o}$ approaches $R_{t}$, the estimated porosity using equation 9 becomes more accurate. If $R_{t}$ is much larger 

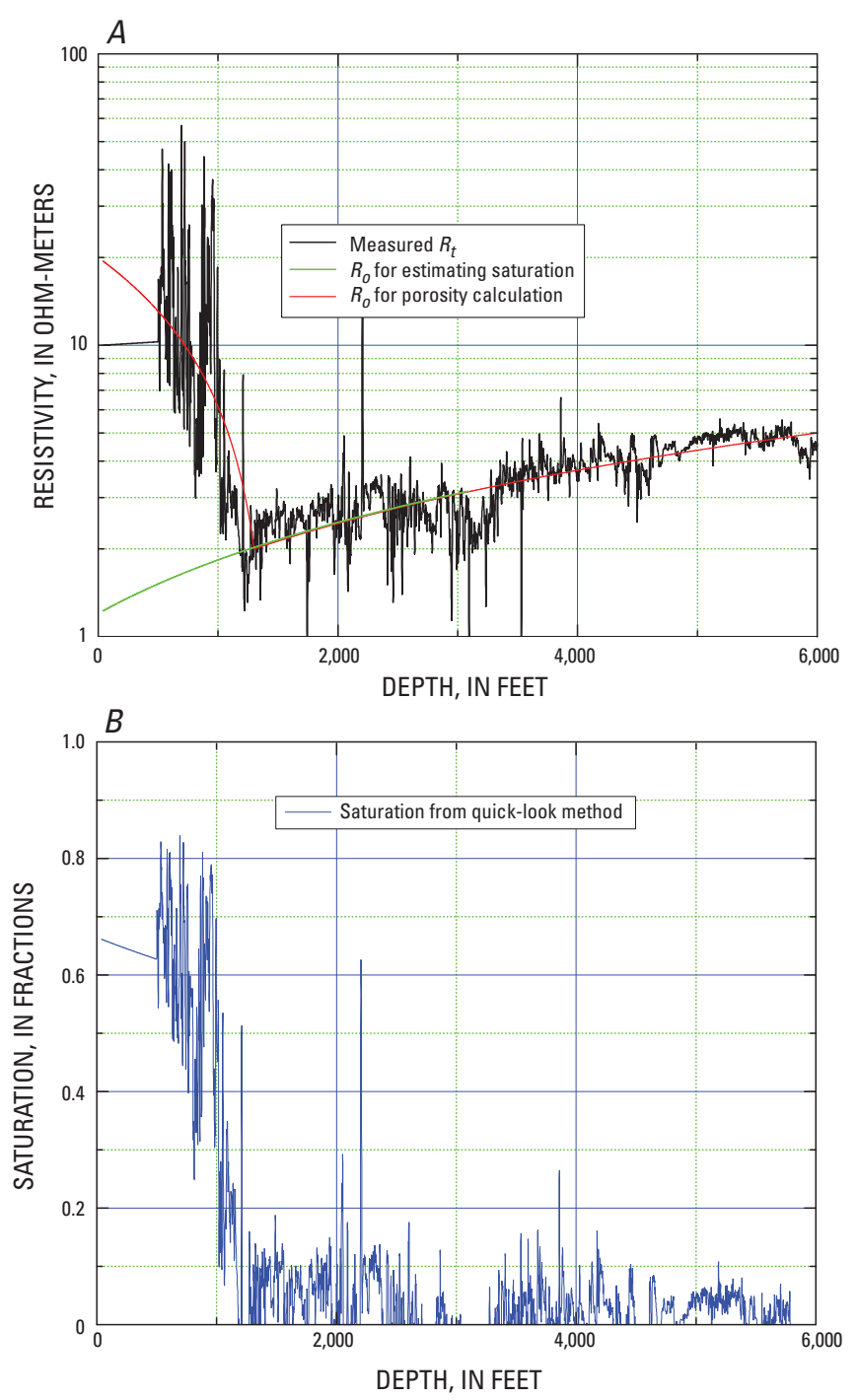

Figure 4. Analysis of a resistivity log from Cape Halkett test well \#1, Alaska North Slope. A. Measured resistivity with assumed $R_{o}$ (base-line resistivity) for various applications. $R_{t}$ (measured resistivity) $\boldsymbol{B}$. Estimated pore saturations using the quick-look method with $R_{o}$ shown by the green line in figure $\mathbf{4 A}$.

than $R_{o}$, the estimated porosity is not accurate. The large $R_{t}$ may be due to low-porosity sediments with low saturation or high-porosity sediments with high saturation, so the two scenarios cannot be differentiated one from the other on the basis of the resistivity log. Consequently, assessing estimated porosity using a judicious choice of $R_{o}$ plays a key role in predicting reasonable velocities. In this report, missing porosities are estimated using a trial and error method by varying $R_{o}$ until a reasonable porosity, comparable to the compaction curve, is derived.

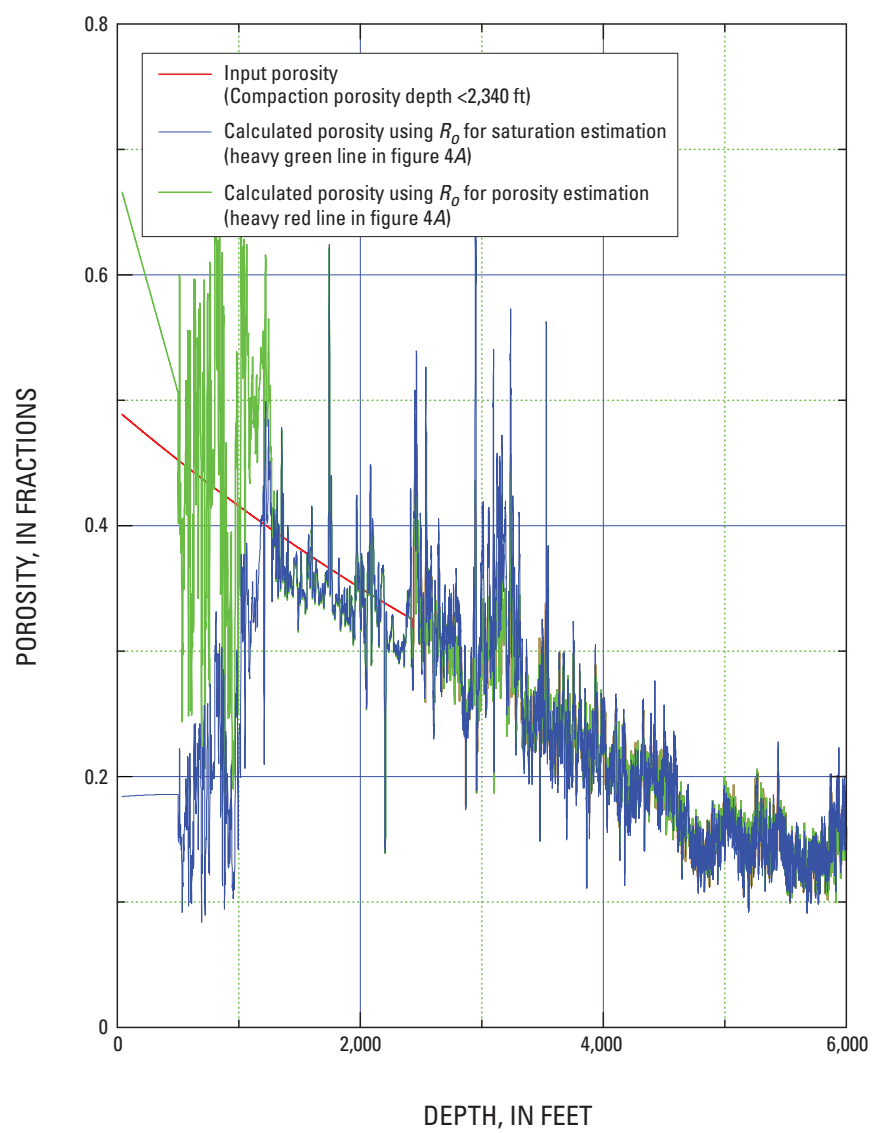

Figure 5. Various estimated porosities and compaction porosity (red line) at Cape Halkett test well \#1, Alaska North Slope. Porosity shown by the green line is derived from the quick-look method using the $R_{o}$ (base-line resistivity) shown by the red line in figure $\mathbf{4 A}$. The porosity, shown by the blue line, is derived from the quick-look method using the $R_{o^{\prime}}$ shown by the green line, in figure $\mathbf{4 A}$.

\section{Least-Squares Fitting Method for Predicting P-Wave Velocity}

Figure $6 A$ shows the relation between resistivity and $\mathrm{P}$-wave velocity at the Colville River 1 well, ANS. The relation for the shallower sediments ranging from 0 to $1,200 \mathrm{ft}$ is given by:

$$
V_{p}=1.23 \log _{10} R_{t}+1.11
$$

where 

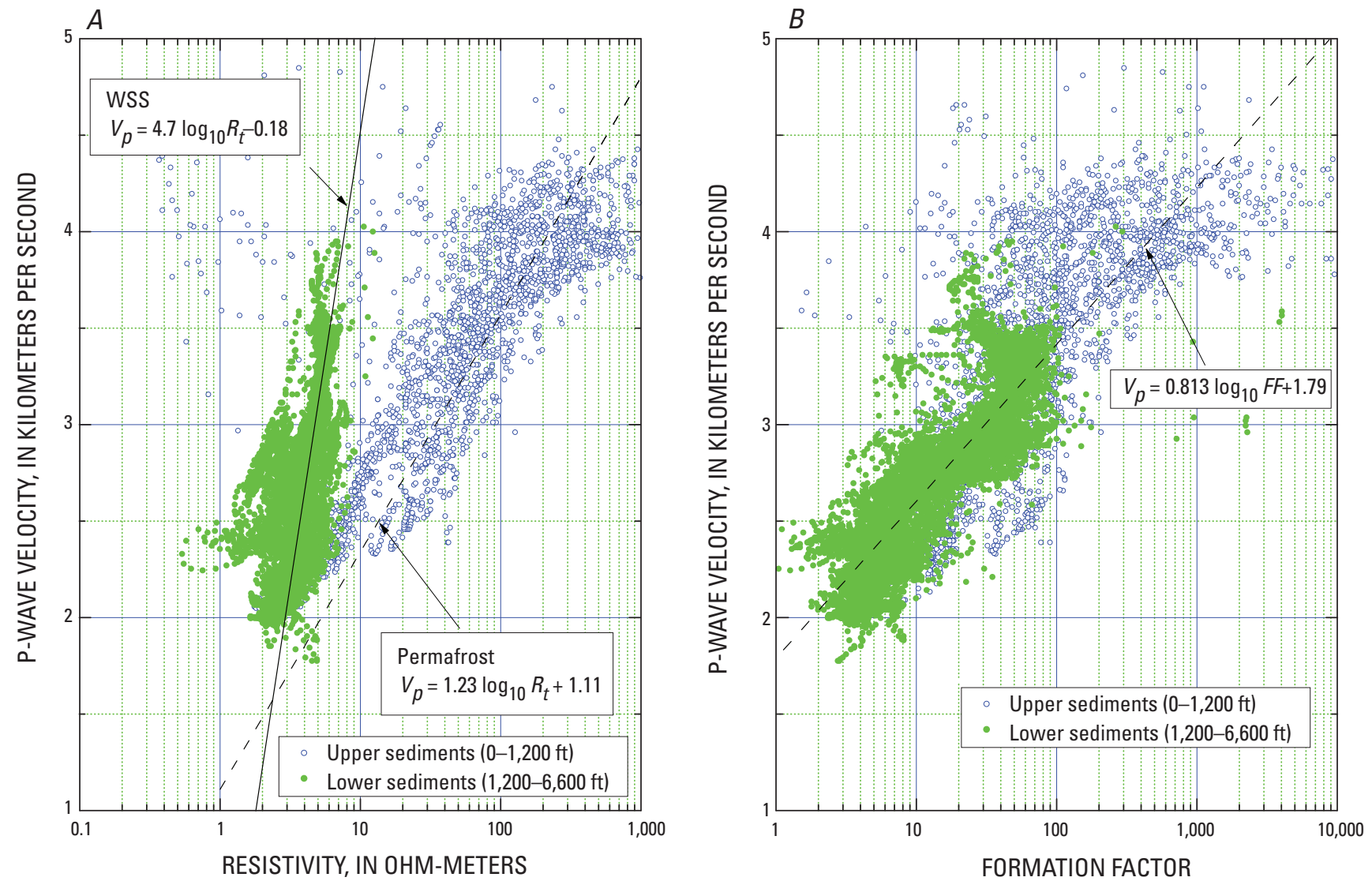

Figure 6. Relationships of resistivity, formation factor, and P-wave velocity at Colville River \#1 well, Alaska North Slope. A. Relationship between resistivity and the P-wave velocity. WSS, water saturated sediment. $V_{p}, \mathrm{P}$-wave velocity in km/s; $R_{t}$, measured resistivity in ohm-m. $\boldsymbol{B}$. Relationship between formation factor and P-wave velocity. FF, formation factor. and

$\mathrm{V}_{p}$ is the $\mathrm{P}$-wave velocity in $\mathrm{km} / \mathrm{s}$,

$R_{t}$ is the measured resistivity in ohm-m.

For sediments with depths greater than $1,200 \mathrm{ft}$, the relation is:

$$
V_{p}=4.7 \log _{10} R_{t}-0.18
$$

The predicted velocities using these two relations are shown in figure $7 A$ along with measured velocities. The general trend of the predicted velocities (the dotted line in figure $7 A$ ) follows the measured velocities well, but the high-frequency components of the predicted velocities are much higher than those of the measured velocities.

Figure $6 B$ shows the relation between the $\mathrm{P}$-wave velocity and $F F$, which are calculated using equation 5 with $R_{o}$ given by the green line in figure $4 A$. Tests indicate that the relation with respect to resistivity rather than $F F$ works better for permafrost, and the relation between $F F$ and the $\mathrm{P}$-wave velocity is more appropriate for sediments below the permafrost at this well. Based on the Colville River \#1 well data, the relation between the $\mathrm{P}$-wave velocity and $F F$ is given by:

$$
V_{p}=0.813 \log _{10} F F+1.79
$$

Predicted velocities using $R_{t}$ for permafrost at depths less than about 1,200 ft and $F F$ for sediments below the permafrost are shown in figure $7 \mathrm{~A}$ as a green line. Predicted velocities follow the measured velocities well, but the high-frequency components of the velocities are much smaller. In this example, using $R_{t}$ is more accurate than using $F F$ for the permafrost. However, because $R_{t}$ depends on the salinity of pore water, it is safer to use $F F$ even in the permafrost interval for other wells of the ANS. One of the reasons that using $R_{t}$ is better than using $F F$ for the Colville River \#1 well is that $F F$ is not accurate in the permafrost interval owing to erroneous density porosity measurements caused by borehole washouts.

Figure 8 shows another example of predicted $\mathrm{P}$-wave velocities computed from the resistivity $\log$ at the Oberon \#1 well, ANS, where there is no available velocity log. Figure $8 A$ indicates that the predicted $\mathrm{P}$-wave velocities using equation 12, shown as the blue line, decrease with depth. This 

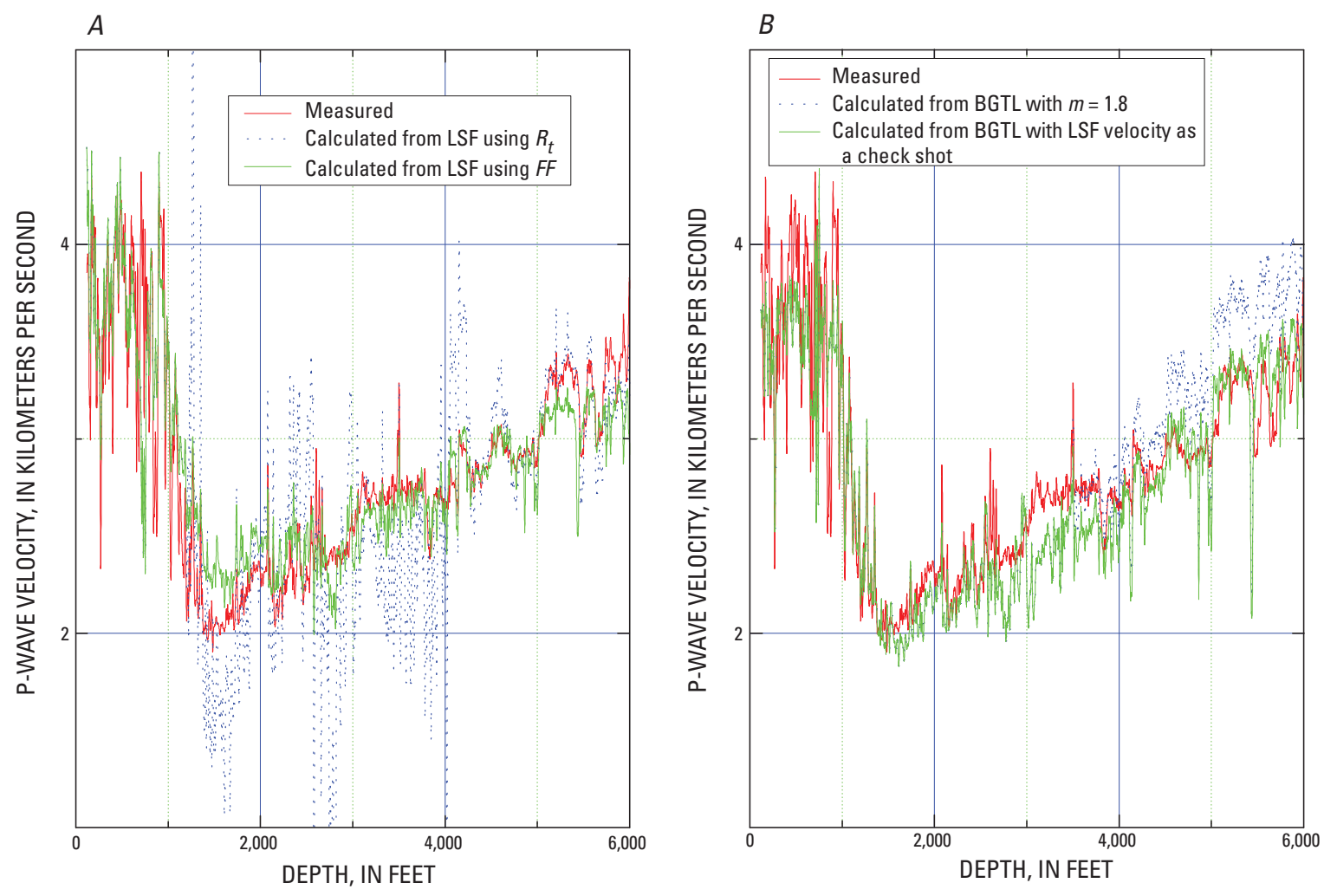

Figure 7. Comparison between measured P-wave velocity and P-wave velocity predicted from resistivity at Colville River \#1 well, Alaska North Slope. A. Measured P-wave velocity and predicted P-wave velocity using leastsquares fitting method (LSF). FF, formation factor; $R_{t^{\prime}}$ measured resistivity in ohm-m. $\boldsymbol{B}$. Measured P-wave velocity, predicted $\mathrm{P}$-wave velocity using the modified Biot-Gassmann theory (BGTL), and P-wave velocity predicted by a combination of BGTL and LSF methods.

is because $R_{t}$ decreases with depth due to a salinity change with depth in this well. Generally, velocities increase with depth. At the Oberon \#1 well, however, the predicted P-wave velocities decrease with depth. This demonstrates that $R_{t}$ is not an appropriate measurement to use in predicting the P-wave velocity, but rather $F F$, which is independent of $R_{w}$, is preferred. The predicted velocity using $F F$ (equation 13 ) is shown in figure $8 A$ as the green line. The predicted velocity increases with depth, however, the high-frequency components of the P-wave velocities are small.

\section{BGTL Method for Predicting P-Wave Velocity}

The BGTL method computes the bulk and shear moduli of sediments by explicitly inserting ice/gas-hydrate saturations estimated from the electrical resistivity log into the BGTL equation. The details of these methods are shown in Lee and Collett (2008). As indicated in Lee and Collett (2008), the BGTL predicts accurate $\mathrm{P}$-wave velocities if accurate porosities are available. In figures $7 B$ and $8 A$, the predicted P-wave velocities using the BGTL method for the Colville River \#1 and Oberon \#1 wells are shown. Figure $8 A$ indicates that the predicted P-wave velocities using the BGTL method exhibit detailed variations with respect to depth, but they are much larger than the P-wave velocities predicted using the LSF method at depths greater than about 3,000 ft. This implies that porosities at the Oberon \#1 well for depths deeper than about 3,000 ft may be underestimated, but the variations of the predicted P-wave velocity with respect to depth appear to be reasonable.

\section{Combination of LSF and BGTL Methods for Predicting P-Wave Velocity}

One advantage of using the LSF method for predicting $\mathrm{P}$-wave velocity is that the average velocity, or the lowfrequency component of the P-wave velocity, is similar to that of the observed velocity. On the other hand, the P-wave velocity predicted using the BGTL method shows the detailed high-frequency component of the P-wave velocity, but either underestimates or overestimates the low-frequency component of the velocity, possibly due to inaccurate porosity measurements and assumptions about other parameters. The 

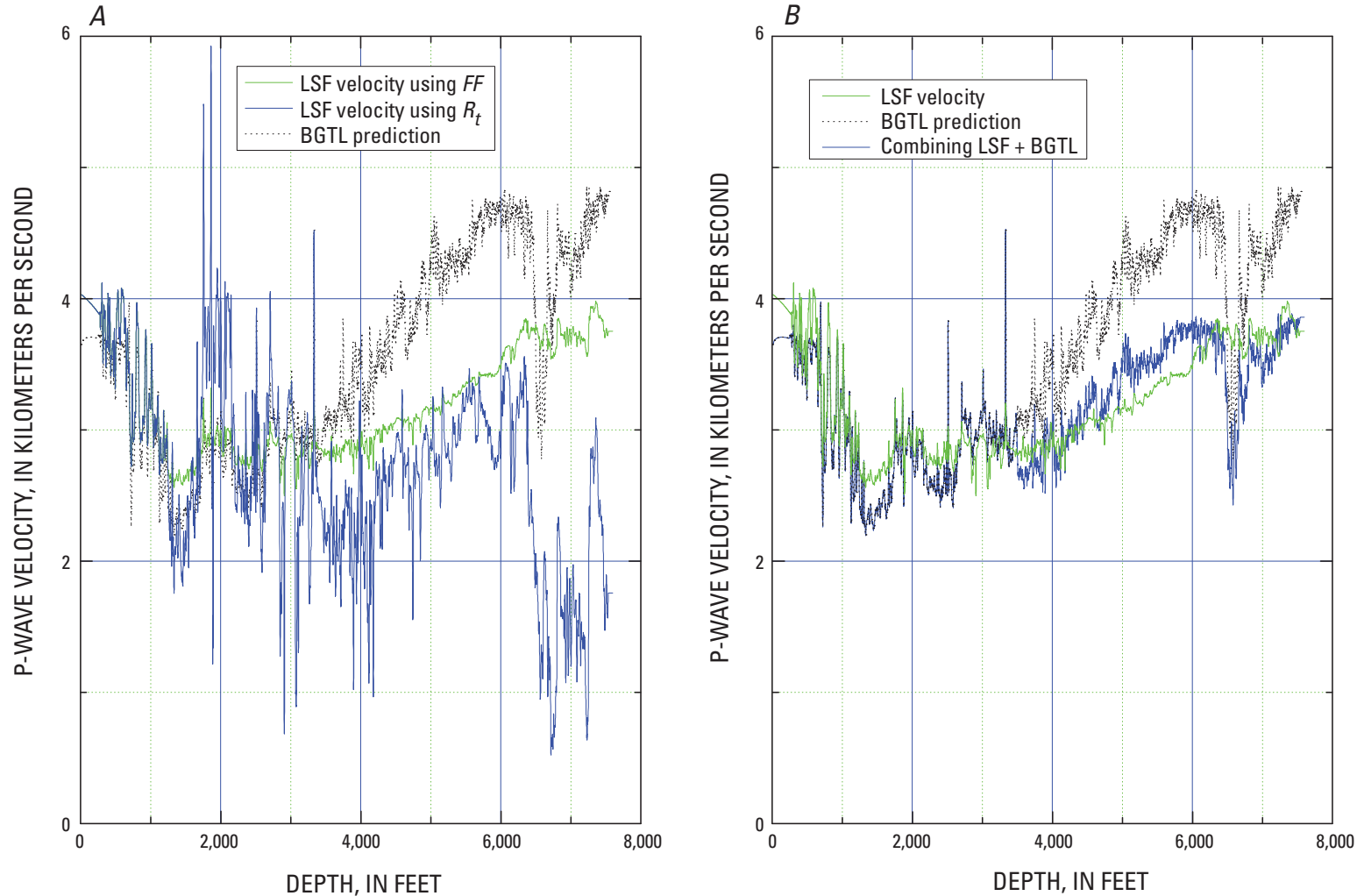

Figure 8. Comparison of P-wave velocity predicted from resistivity using various methods at Oberon \#1 well, Alaska North Slope. $\boldsymbol{A}$. The P-wave velocity predicted from the least-squares fitting method (LSF) using measured resistivity $\left(R_{t}\right)$, calculated formation factor $(F F)$, and predicted P-wave velocity using the modified Biot-Gassmann theory (BGTL). B. Predicted P-wave velocity from the LSF method using $F F$, predicted P-wave velocity using the BGTL, and P-wave velocity predicted by a combination of the BGTL and LSF methods.

method proposed in this report is to combine the predicted velocities from the BGTL and LSF in a sensible way. The velocities, shown as the solid green line in figure $7 B$, were calculated by combining the high-frequency components of velocity from the BGTL method and low-frequency components from the LSF method for depths greater than 3,000 ft. For depths less than 3,000 ft, the velocities predicted from the BGTL method are used. Combining the velocities computed with the two methods is accomplished by treating the velocity predicted from the LSF method as check-shot data and the velocity predicted from the BGTL method as measured data.

Various combinations of methods were utilized to predict the missing P-wave velocities in the ANS wells. Another example of combining the velocities predicted by the LSF method and by the BGTL method is shown in figure $8 B$ for the Oberon \#1 well. Figure 9 shows 2-D seismic data around the Oberon \#1 well overlain with a synthetic seismogram generated using the predicted P-wave velocity shown in figure $8 B$ (blue curve). The quality of the 2-D seismic data for two-way travel times less than 1,000 milliseconds (ms) is not good, so the tie between synthetic and seismic data is questionable. However, agreement between the synthetic and seismic data for major markers below $1,000 \mathrm{~ms}$ is fairly good.

\section{Differentiating Ice from Gas Hydrate in Permafrost}

\section{Thermal Conductivity of Porous Medium}

Thermal conductivity is a property that expresses the heat flow $(q)$ through a material over time given a certain temperature gradient. That is:

where

$$
q=\frac{d Q}{A d t}=k \frac{d T}{d z}
$$

$Q$ is thermal energy, $A$ is the cross-sectional area, $t$ is time, $T$ is temperature, and $\mathrm{z}$ is distance. With $T$ in degrees Kelvin and $z$ in meters, the thermal conductivity $k$ is expressed as $W / m^{\circ} K$.

The thermal conductivity of multi-phase materials, such as sediments composed of grains and water, can be calculated 


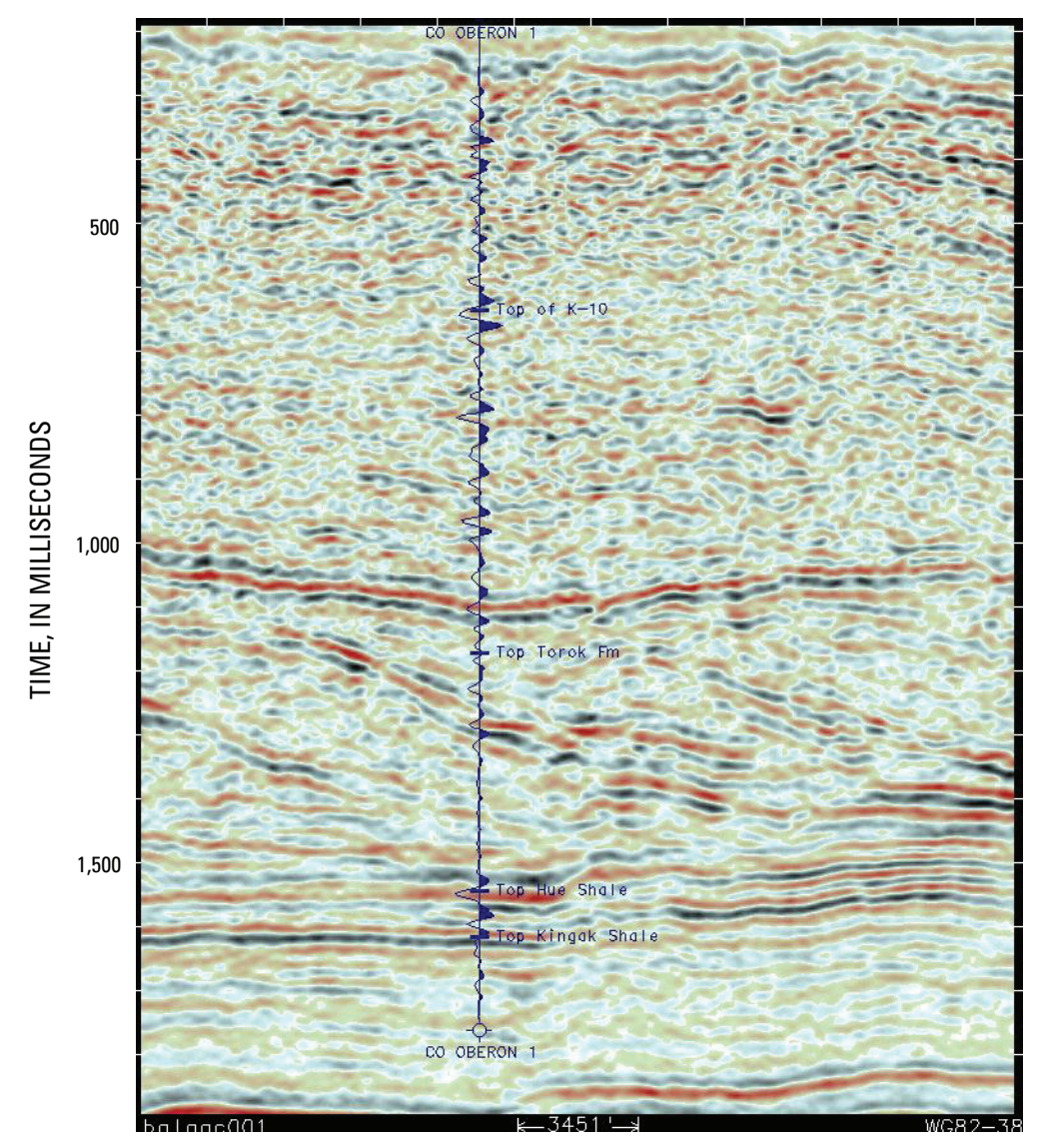

Figure 9. 2-D seismic section overlain with a synthetic seismogram at Oberon \#1 well, Alaska North Slope. The synthetic seismogram was generated using the $\mathrm{P}$-wave velocity shown by the blue line in figure $8 B$.

using the geometrical mean of the conductivities of the constituent components (Lachenbruch and others, 1982) and can be written as:

$$
k=\prod_{j=1}^{n} k_{j}^{\alpha_{j}} \text { with } \sum_{j=1}^{n} \alpha_{j}=1.0
$$

where

$n$ is the number of constituent components, $k_{j}$ is the thermal conductivity of the $j$-th component, and $\alpha_{j}$ is the fractional volume of the $j$-th component.

The thermal conductivities of ice, gas hydrate, and water depend on the crystal structure and temperature of the formation. The in-situ temperature of sediments in the ANS within the permafrost and gas-hydrate stability zone ranges from approximately $-11^{\circ} \mathrm{C}$ to $12^{\circ} \mathrm{C}$. In this temperature range, the thermal conductivities of ice, gas hydrate, and the constituents of the sediments are almost constant. At $-10^{\circ} \mathrm{C}$, the thermal conductivity of ice is $2.23 \mathrm{~W} / \mathrm{m}^{\circ} \mathrm{K}$ and is 0.49 $\mathrm{W} / \mathrm{m}^{\circ} \mathrm{K}$ for gas hydrate (Sloan and Koh, 2008). The conductivity of quartz is $7.7 \mathrm{~W} / \mathrm{m}^{\circ} \mathrm{K}$ (Hartmann and others, 2005), about $0.25 \mathrm{~W} / \mathrm{m}^{\circ} \mathrm{K}$ for clay (Cook, written commun., 2005), and $0.56 \mathrm{~W} / \mathrm{m}^{\circ} \mathrm{K}$ for water at room temperature.
According to Judge (1973), the thermal conductivity of shale within permafrost zones in northern Canada is about 0.35 times that of quartz. If it is assumed that the sediments in the permafrost zone have a porosity of 0.5 (50 percent) and a clay volume content of 0.5 (50 percent), the calculated thermal conductivity of shale using equation 15 is $0.98 \mathrm{~W} / \mathrm{m}^{\circ} \mathrm{K}$, or about 0.32 times that of quartz. This calculation indicates that the measured thermal conductivity is close to the calculated conductivity using equation 15 . The average measured thermal conductivities of sediments at Blake Ridge, mostly marine shale, are about $1.0 \mathrm{~W} / \mathrm{m}^{\circ} \mathrm{K}$ (Ruppel and others, 1995), which is also close to that calculated using the geometrical mean of the constituent components. Therefore, the thermal conductivity of constituent components and equation 15 are deemed to be valid in this study.

\section{Estimating Thermal Conductivity Using Logs}

If the heat flow in the area is assumed to be constant, in other words, if there are no heat sources or sinks, the thermal conductivity of sediments can be estimated using equation 14 
as:

$$
k=\frac{q}{d T / d z}=\frac{q_{r e f}}{d T / d z}=\frac{q_{r e f}}{G}
$$

where

$q_{\text {ref }}$ is a reference heat flow calculated at a certain depth, and $G$ is the thermal gradient.

In this study, an average value is used for the reference heat flow, which is calculated by integrating equation 16 for intervals where high ice concentrations are estimated from the resistivity log. Using equations 15 and 16, the reference heat flow is given by:

$q_{\text {ref }}=\frac{1}{\left(d_{2}-d_{1}\right)} \int_{d_{1}}^{d_{2}} k_{\text {quartz }}^{\alpha 1}(z) k_{\text {clay }}^{\alpha 2}(z) k_{\text {ice }}^{\alpha 3}(z) k_{\text {water }}^{\alpha 4}(z) G(z) d z$

where

$$
\alpha_{1}=(1-\phi)\left(1-C_{v}\right), \alpha_{2}=(1-\phi) C_{v}, \alpha_{3}=S \phi, \text { and } \alpha_{4}=(1-S) \phi
$$

with

$C_{v}$ being the volume clay content, $S$ being the ice saturation in the pore space, and $\phi$ being the porosity of sediment.

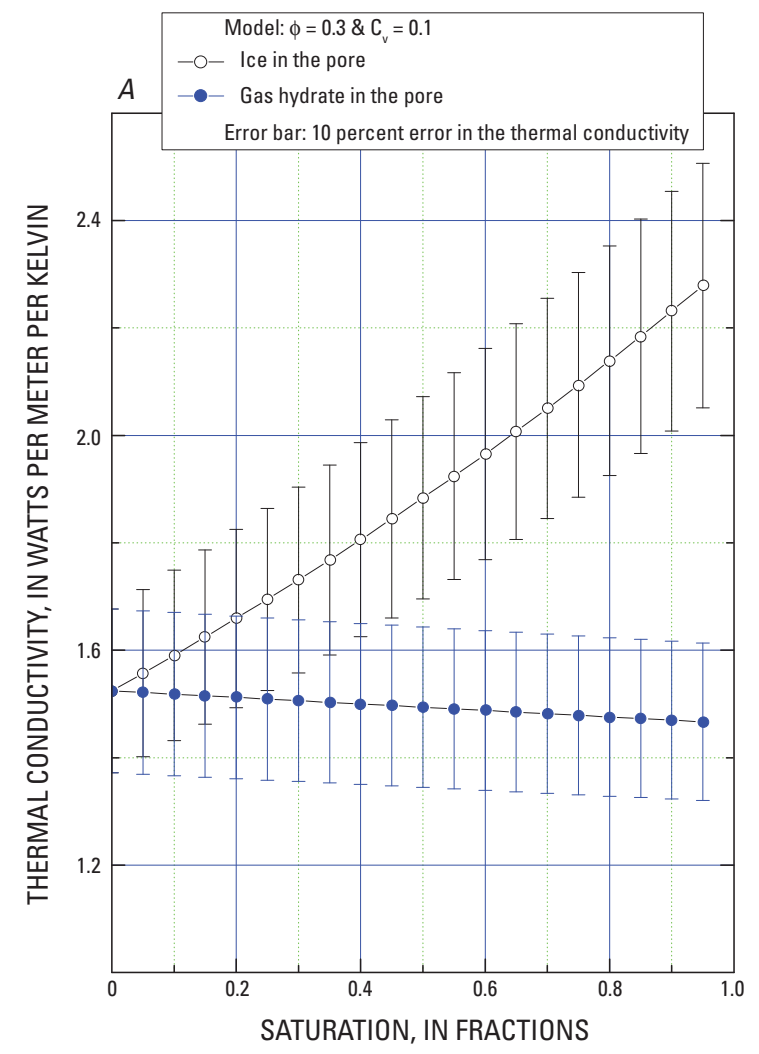

\section{Error Analysis}

Theoretically, the thermal conductivities can discriminate ice from gas hydrate in the pore space because the thermal conductivity of ice is about four times that of gas hydrate. Real data, however, contain a certain amount of uncertainty, and thus, the proposed method is not accurate in all situations.

Figure 10 shows modeled thermal conductivities for 30- and 40-percent-porosity sediments with respect to ice/ gas-hydrate saturation. In this analysis, it is assumed that the uncertainty associated with the estimated thermal conductivity is about 10 percent, that is $\Delta k / k=0.1$. Figure $10 A$ indicates that the thermal conductivities of the ice-bearing sediments overlap the thermal conductivities of the gas-hydrate-bearing sediments for saturations less than about 40 percent for 30 -percent porosity, if $\Delta k / k=0.1$. For 40 -percent porosity, the overlap occurs at about 30-percent saturation (fig. 10B). Porosity expected inside the overlapping zones at ANS is between 35 to 45 percent. Figure 10 suggests that to accurately discriminate ice from gas hydrate using the thermal conductivity, the minimum saturation has to be approximately 30 to 40 percent. If saturations are less than about 30 to 40 percent, the difference in thermal conductivity between iceand gas-hydrate-bearing sediments is within the limits of the uncertainty. Theory predicts that as porosity and saturation

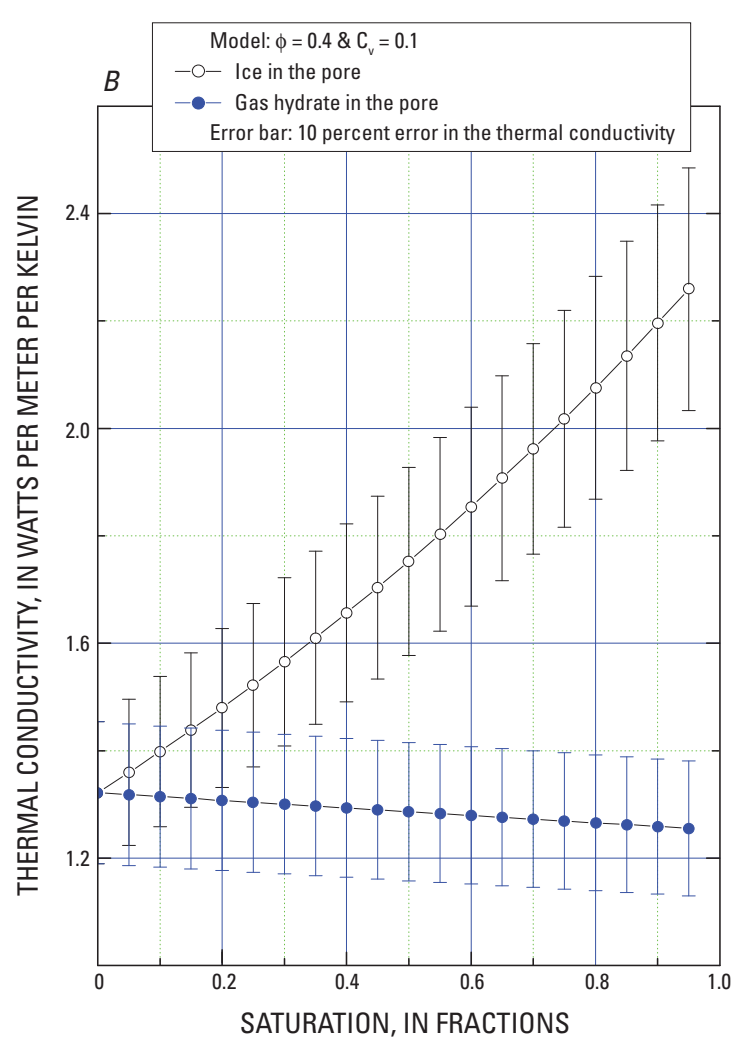

Figure 10. Calculated thermal conductivity as a function of gas-hydrate/ice saturation. $\boldsymbol{A}$. Model parameters for the sediments are 30-percent porosity $(\phi)$ and 10 -percent clay volume content $\left(C_{v}\right)$. B. Model parameters for the sediment are 40 -percent porosity $(\phi)$ and 10 -percent clay volume content $\left(C_{v}\right)$. 
increase, the ability to discriminate ice from gas hydrate in the pore increases.

The accuracy of calculated thermal conductivity due to error in the saturation can be written as:

$$
\frac{d k}{d s}=\phi\left(\ln \left(k_{\text {ice }}\right)-\ln \left(k_{\text {water }}\right)\right) k \text { or } \frac{\Delta k}{k}=\phi\left(\ln \left(k_{\text {ice }}\right)-\ln \left(k_{\text {water }}\right)\right) \Delta S
$$

where

$k_{i c e}$ and $k_{\text {water }}$ are the thermal conductivities of ice and water, respectively.

Assuming 40-percent porosity, equation 18 yields $\Delta k / k$ $=0.55 \Delta S$. If the uncertainty of the saturation is about 20 percent, the fractional error in the thermal conductivity is about 11 percent. This implies that the calculated thermal conductivity can have 10-percent error if the saturation of ice has about 20-percent error.

Similar to equation 18 , the calculated error in thermal conductivity assuming gas hydrate in the pore can be written as:

$$
\frac{\Delta k}{k}=\phi\left(\ln \left(k_{\text {hyd }}\right)-\ln \left(k_{\text {water }}\right)\right) \Delta S
$$

where

$k_{\text {hyd }}$ is the thermal conductivity of the gas hydrate.

Assuming 40-percent porosity, equation 19 yields $\Delta k / k=$ $-0.05 \Delta S$. If the uncertainty of saturation is about 20 percent, the fractional error in the thermal conductivity is about 1 percent. This implies that the calculated thermal conductivity assuming gas hydrate in the pore space is insensitive to the saturation because the conductivities of water and gas hydrate are similar.

The thermal conductivity error associated with the error in the porosity, assuming ice in the pore space, can be written as:

$$
\frac{\Delta k}{k}=\left[\left(C_{v}-1\right) \ln k_{\text {quartz }}-C_{v} \ln k_{\text {clay }}+S\left(\ln k_{\text {ice }}-\ln k_{\text {water }}\right)\right] \Delta \phi
$$

where

$k_{\text {quart }}$ and $k_{\text {clay }}$ are the thermal conductivities of quartz and clay, respectively.

For $C_{v}=0, S=0.4$, and $\Delta \phi=0.05$, the fractional error in the thermal conductivity, $\Delta k / k$, equals -0.07 when using $k_{\text {quart }}$ is $7.7 \mathrm{~W} / \mathrm{m}^{\circ} \mathrm{K}$ (Hartmann and others, 2005). The thermal conductivity error associated with the error in porosity increases as saturation decreases when ice is used as the pore saturant, whereas it slightly increases as saturation increases when gas hydrate is used as the pore saturant. This analysis indicates that accurate sediment porosities are required to discriminate ice from gas hydrate in the pore space when the saturation is low.

A larger source of error in the conductivity comes from the uncertainty in the clay volume when porosity is small. The conductivity error associated with the uncertainty in the clay volume is given by:

$$
\frac{\Delta k}{k}=(1-\phi)\left(\ln k_{\text {clay }}-\ln k_{\text {quartz }}\right) \Delta C_{v}
$$

Equation 21 indicates that the fractional error in the thermal conductivity increases as porosity decreases. Assuming $C_{v}=0.2, \phi=0.3$, and $\Delta C_{v}=0.1$, the fractional error in the thermal conductivity is about -0.17 , which is large. This implies that estimating thermal conductivity is practical, if an accurate clay volume can be estimated.

\section{Example from Husky Oil Atigaru PT 1 Well}

The porosity and resistivity measured from the Husky Oil Atigaru PT 1 well, ANS, are shown in figure 11. Because the bulk densities were measured for depths deeper than approximately 2,300 $\mathrm{ft}$ at this well, the porosities of the shallow part of the well are substituted by porosities calculated using the local compaction curve. These porosities are shown in figure $11 A$. The measured resistivity and the base-line resistivity used for the quick-look method are shown in figure $11 B$. The clay volume content was estimated from the gamma ray log using the formula pertinent to Tertiary clastics (Western Atlas International, Inc., 1995). The ice/gas-hydrate saturations estimated from the resistivity log using the quick-look method (Collett, 2000) are shown in figure 12B.

Figure $12 A$ shows the measured in-situ temperatures at the Husky Oil Atigaru PT 1 well and the theoretical gashydrate phase boundary for pure methane. The temperature at the base of ice-bearing permafrost is about $-1^{\circ} \mathrm{C}$, so figure $12 \mathrm{~A}$ suggests that ice and gas hydrate can coexist for depths between approximately $750 \mathrm{ft}$ and $1,250 \mathrm{ft}$.

Figure $12 B$ shows estimated thermal conductivities using the temperatures shown in figure $12 A$, saturations shown in figure $12 B$, and the porosities shown in figure $11 A$. The reference heat flow is calculated for depths between 400 and $600 \mathrm{ft}$, where about 90 percent of pore space is saturated with ice. For comparison, the calculated thermal conductivities assuming 100-percent ice saturation (red line) and 100-percent gas-hydrate saturation (blue line) are also shown in figure $12 B$. Because the thermal conductivities of gas hydrate and water are similar, the calculated thermal conductivity assuming water in the pores is similar to that for gas hydrate.

For depths less than about 1,200 ft, the thermal conductivities estimated from the temperature agree better with the thermal conductivities calculated assuming ice, rather than gas hydrate, in the pores except at the depth of $800 \mathrm{ft}$. At the depth of $800 \mathrm{ft}$, the thermal conductivity estimated from the temperature agrees with that calculated assuming gas hydrate in the pores. Although there is no independent confirmation of gas hydrate comingled with ice at this well site, such as from the mud log, this analysis demonstrates that the thermal conductivity potentially could be used to discriminate gas hydrate from the ice in the overlapping zone.

The estimated thermal conductivities for depths between $1,250 \mathrm{ft}$ and $1,500 \mathrm{ft}$ are slightly smaller than those calculated 

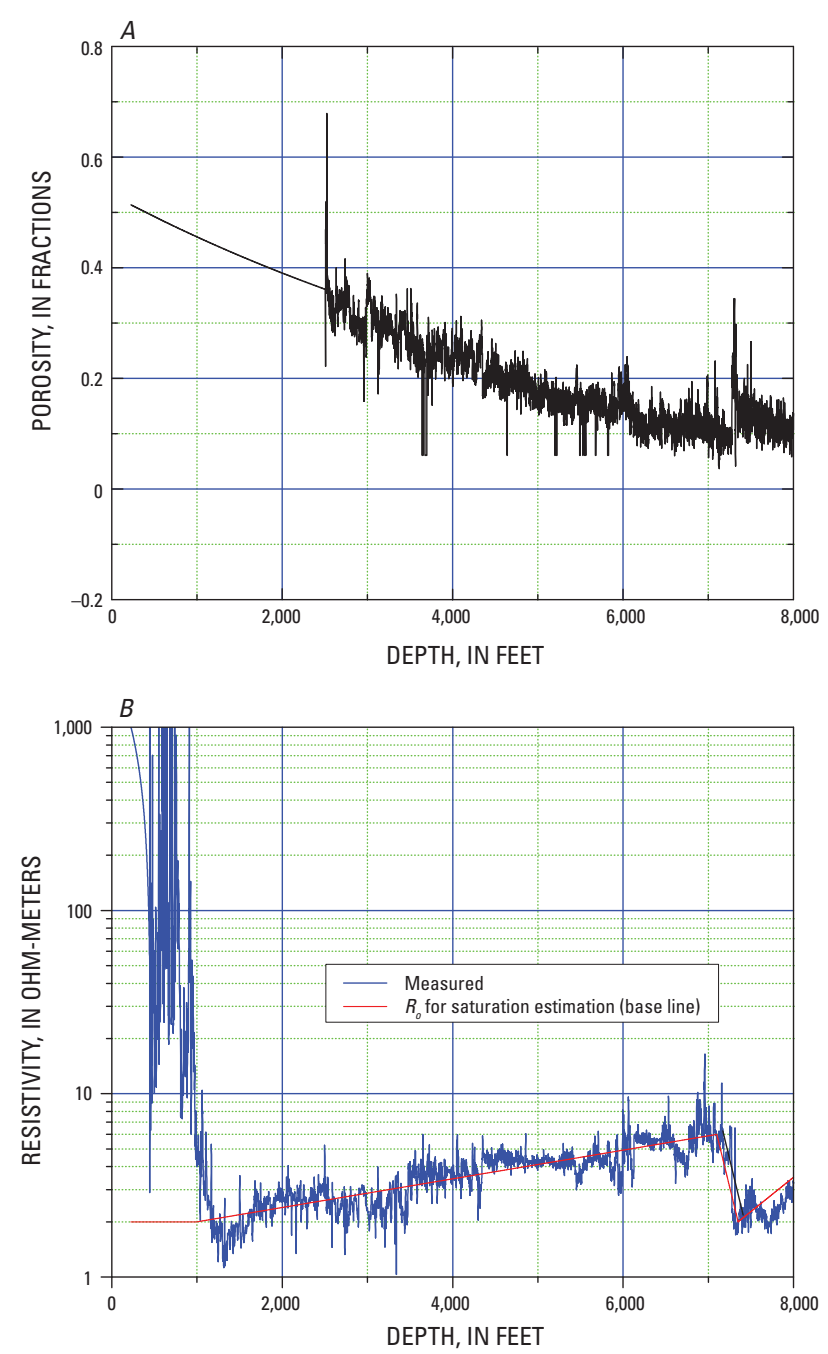

Figure 11. Well logs for Husky Oil Atigaru PT 1 well, Alaska North Slope. A. Adjusted porosity and compaction porosity. $\boldsymbol{B}$. Measured resistivity and assumed resistivity of watersaturated sediment $\left(R_{o}\right)$ for the quick-look method used to estimate saturation.
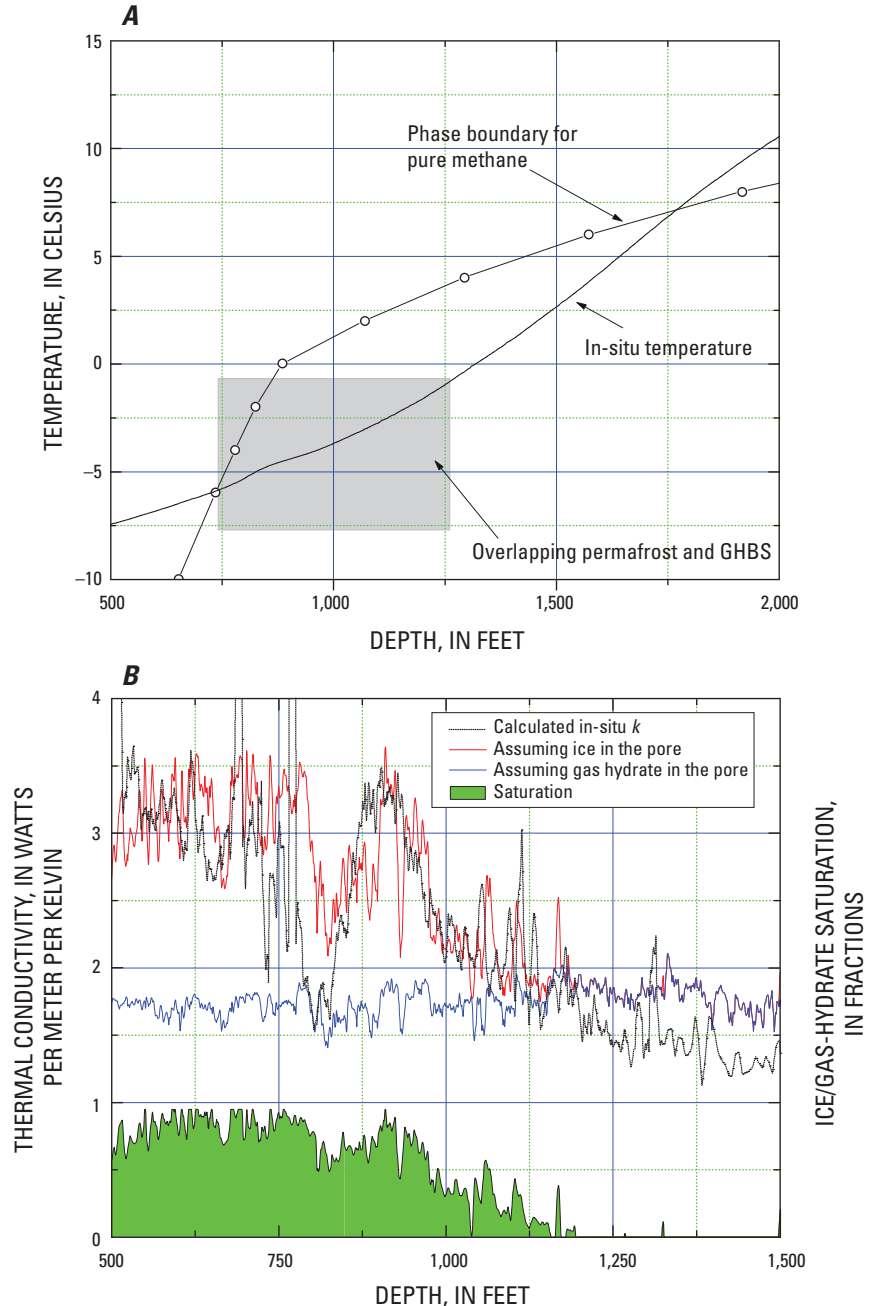

Figure 12. Graph showing gas-hydrate phase boundary, temperature, permafrost, and thermal conductivity at Husky Oil Atigaru PT 1 well, Alaska North Slope. A. Gas-hydrate phase boundary and measured temperature. GHBS, gashydrate-bearing sediment. $\boldsymbol{B}$. Theoretically calculated thermal conductivities with various pore saturants and calculated thermal conductivity using the measured thermal gradient assuming that there are no heat sources or sinks. $k$, thermal conductivity. assuming water in the pores (there are no estimated saturations in this interval). As discussed earlier, error analysis indicates that the calculated thermal conductivities assuming gas hydrate in the pores change little even with large errors in the saturation or in porosity, due to the fact that the thermal conductivity of water is similar to that of gas hydrate. On the other hand, the calculated conductivities assuming ice in the pores (red curve in figure 12) can change by10 percent, if the error in the saturation is about 20 percent. Therefore, the calculated conductivity assuming gas hydrate in the pores is more accurate. The large discrepancy between the estimated and calculated thermal conductivities for dominantly watersaturated sediments at depths deeper than 1,200 ft in figure 12 may be caused by error in the calculated clay volume and the conductivity of clay. 


\section{Developing Acoustic Models for Reservoir and Seal}

\section{Reservoir and Seal}

As discussed by Lee and Collett (2005), gas hydrate usually accumulates in the more porous and cleaner sandstone intervals of the sediments, and this characteristic has also been observed in the gas-hydrate accumulations on the Alaska North Slope. Therefore, to characterize the reservoir, acoustic properties of a clean sandstone interval are required, whereas acoustic properties of a shaly sand are required to characterize the seal.

Figure $13 A$ shows the $\mathrm{P}$-wave velocity, bulk density porosity, and clay volume content for sediments within GHSZ at the Arco Till \#1 well, ANS. As shown in figure 13A, the high P-wave velocity interval corresponds to a high-porosity interval with low clay volume content. Except for anomalously high porosity spikes, the log responses are of good quality.

Figure $13 A$ indicates that the cleaner sediments are associated with high $\mathrm{P}$-wave velocities and high-density porosities. On the other hand, the shaly sands are associated with lower $\mathrm{P}$-wave velocities and lower density porosities.

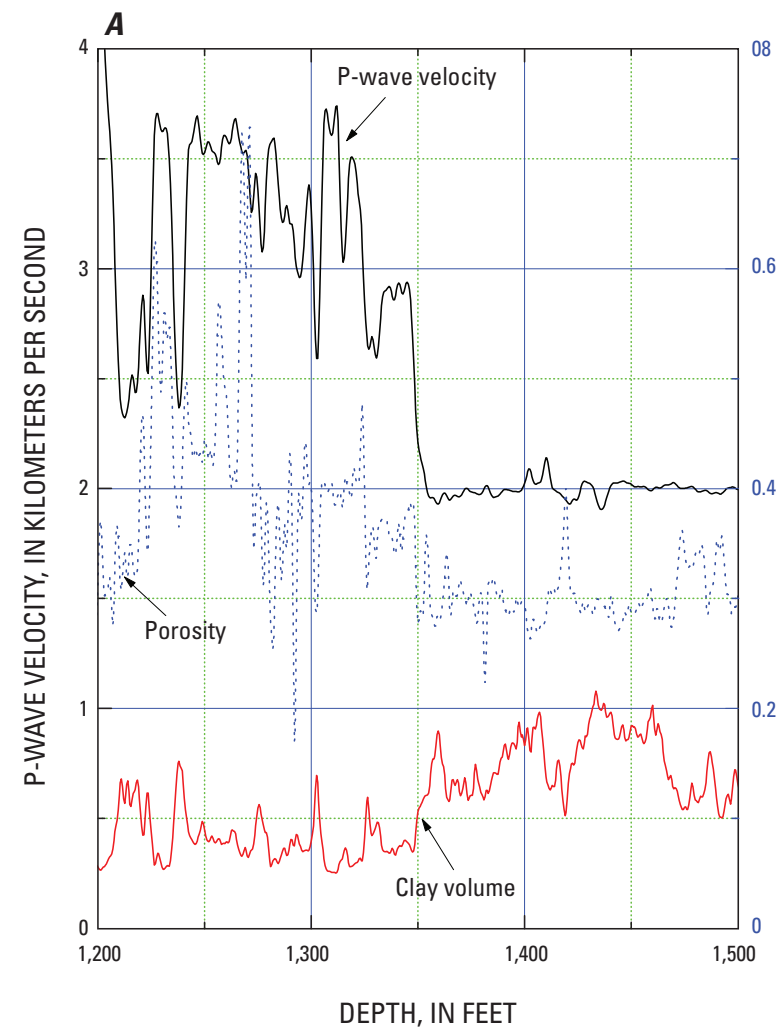

In order to develop an acoustic model of the reservoir with respect to gas-hydrate accumulations, the P-wave baseline velocity of clean sand, the velocity expected in the case that there is no gas hydrate in the pore, is required. Because no adequate well logs were found for deriving base-line velocities, the base-line velocity was derived from the velocities of GHBS present in the assessment area by accounting for the effect of gas hydrate in the pores. Incorporating the gas-hydrate saturation estimated from the resistivity log, the base-line P-wave velocity was calculated from measured velocity shown in figure $13 A$ using the BGTL. The calculated velocities accounted for gas hydrate in the pores and measured porosities were averaged in the clean sandstone interval between $1,200-\mathrm{ft}$ and 1,350-ft depth, and the averaged P-wave velocity and porosity pair is shown as a solid star in figure $13 B$, referred to as the reservoir property. The $\mathrm{P}$-wave velocities and porosities underlying the reservoir, shown in figure $13 \mathrm{~A}$, were averaged, and the averaged $\mathrm{P}$-wave velocity and porosity pair is shown as an open star in figure $13 B$, referred to as the seal property. The porosity and the P-wave velocity for the seal are 0.32 and $2.2 \mathrm{~km} / \mathrm{s}$, respectively, and the porosity and the P-wave velocity for the reservoir are 0.42 and $1.87 \mathrm{~km} / \mathrm{s}$, respectively. Note that the P-wave velocity of the seal in figure $13 B$ is about

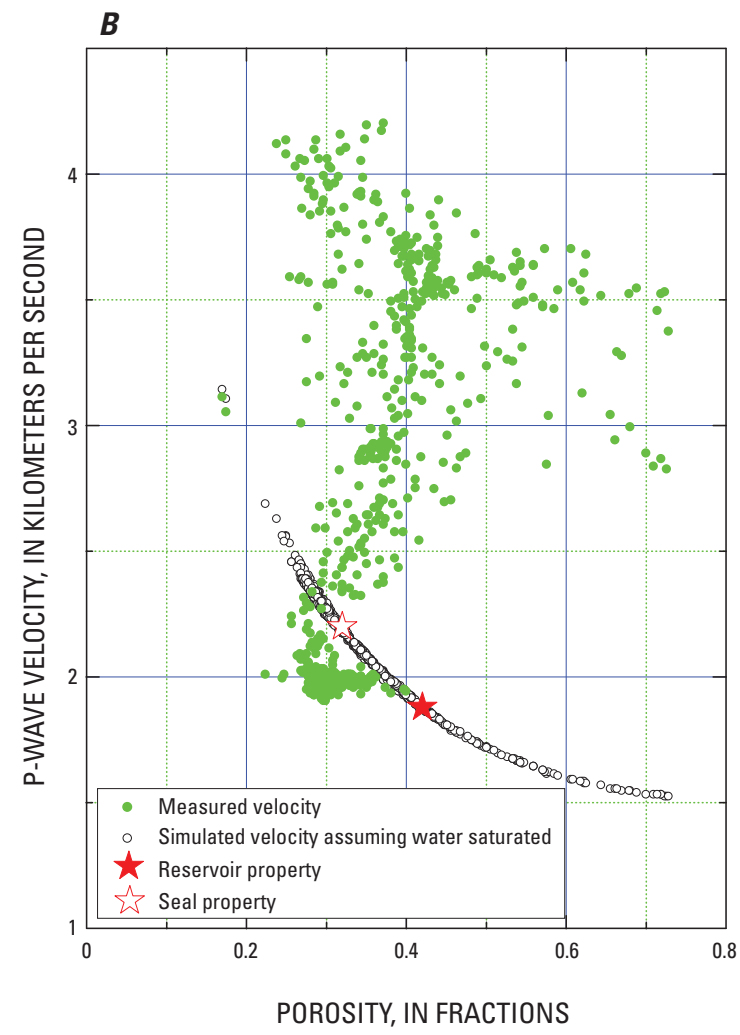

Figure 13. Reservoir and seal models derived for Arco Till \#1 well, Alaska North Slope. A. Measured P-wave velocity, density porosity, and clay volume. $\boldsymbol{B}$. Measured P-wave velocities with the velocities of seal and reservoir indicated. 
10 percent higher than the $\mathrm{P}$-wave velocity of the reservoir at the Arco Till \# 1 well, shown in figure $13 A$.

As in the previous study in the Milne Point area (Lee, 2005), the P-wave velocity of the seal is higher than that of the reservoir at this well. To determine whether this kind of acoustic property for the seal and reservoir is typical in the assessment area, acoustic properties of deeper intervals from surrounding wells are examined, and appendix 2 shows two additional models derived from deeper reservoirs. On the basis of three models, it is determined that the seal and reservoir properties shown in figure $13 B$ are representative in the assessment area.

It is important to note that the P-wave velocity of the water-saturated reservoir is lower than that of the seal. As discussed in the next section, this is the property that is responsible for the seismic amplitude blanking frequently associated with marine gas-hydrate-bearing sediments (Dillon and others, 1993). Although the porosity and clay volume content of individual reservoirs differ from the typical reservoir properties described here, the fact that the P-wave velocities of the seals are greater than those of the reservoirs without gas hydrate is generally valid in this area.

\section{Elastic Velocities and Seismic Reflection Coefficient}

Usually gas hydrates accumulate in shallow, unconsolidated sediments because of the pressure and temperature conditions of the GHSZ. Gas-hydrate-bearing sediments remain unconsolidated as gas hydrate accumulates to very high saturations. In this report, the BGTL is used to predict velocities of gas-hydrate-bearing reservoirs.

In order to predict the velocity of gas-hydrate-bearing sediments for a given gas-hydrate concentration, the properties of the base-line sediments (no gas hydrate or gas in the pore space) are required, and the pertinent parameters for the BGTL should be derived from the elastic properties of the base-line sediments. Based on the results shown in figure 13B, the BGTL parameters with $m=1.8$ and $\delta=1$ with reservoir parameters derived from figure $13 B$ are used throughout this report for the sake of convenience. However, depending on the characteristics of local sediments, different $m$ and $\delta$ should be used to more accurately predict velocities. Figure 14 shows the calculated velocities and reflection coefficients with respect to gas-hydrate saturation at a differential pressure of 4 mega Pascals (MPa). Table 2 shows the elastic constants for each component of the sediments used for modeling in this study.

It is assumed that a seismic stacked section represents a filtered version of normal incidence reflection coefficients. P-wave reflection amplitudes depend on the impedance contrast of the strata and the angle of incidence of the wave. Figure 14 shows the normal incidence P-P reflection coefficients for GHBS with respect to saturation. For GHBS, amplitude variation with respect to gas-hydrate saturation is complicated. The reflection amplitude for the GHBS decreases
Table 2. Elastic constants used in this study.

\begin{tabular}{|c|c|}
\hline $\begin{array}{l}\text { Component used } \\
\text { for modeling }\end{array}$ & $\begin{array}{c}\text { Values } \\
\text { used }\end{array}$ \\
\hline Shear modulus of quartz & $45 \mathrm{Gpa}$ \\
\hline Bulk modulus of quartz & $36 \mathrm{GPa}$ \\
\hline Shear modulus of clay & $6.85 \mathrm{GPa}$ \\
\hline Bulk modulus of clay & $20.9 \mathrm{GPa}$ \\
\hline Shear modulus of hydrate & $2.54 \mathrm{GPa}$ \\
\hline Bulk modulus of hydrate & $6.41 \mathrm{GPa}$ \\
\hline Density of quartz & $2.65 \mathrm{~g} / \mathrm{cm}^{3}$ \\
\hline Density of clay & $2.58 \mathrm{~g} / \mathrm{cm}^{3}$ \\
\hline Density of hydrate & $0.91 \mathrm{~g} / \mathrm{cm}^{3}$ \\
\hline
\end{tabular}

as the gas-hydrate saturation increases from zero saturation. At about 30-percent saturation, the reflection coefficient is almost zero, and the amplitude increases with the opposite polarity as gas-hydrate saturation further increases. If gas-hydrate saturations are between 30 percent and 40 percent, figure 14 indicates that the reflection amplitude is very small. In other words, seismic amplitude blanking occurs as described in Dillon and others (1993) and Lee and Dillon (2001). Figure 14 also indicates that the normal incidence amplitude is not a good parameter to use in estimating low gas-hydrate saturations. On the other hand, the normal incidence amplitude is a good parameter for gas-hydrate saturations above about 60 percent. Note that the magnitude of reflection coefficient at 0 -percent gas-hydrate saturation is as great as at saturation of approximately 60 percent. Consequently, the polarity of the reflection plays an important role in estimating gas-hydrate saturation.

\section{Developing a Method of Estimating Gas-Hydrate Saturation and Thickness}

Lee and others (in press) demonstrated that reflection amplitudes mainly depend on the level of gas-hydrate saturation, thickness of the reservoir, and input seismic frequency. Figure $15 \mathrm{~A}$ shows a relation between true twoway travel time thickness of a reservoir and the gas-hydrate saturation using the reservoir and seal model shown in figure 14 and a $60-\mathrm{Hz}$ (hertz) Ricker wavelet. As the gas-hydrate saturation changes, the peak amplitude, as well as peak-totrough time, changes for a given reservoir thickness. For a given saturation, the peak amplitude and peak-to-trough time vary with the thickness of a reservoir. Thus, the variations in peak-to-trough times and amplitudes yield information about the saturations and thicknesses of the reservoirs. Figure $15 B$ shows the relation with respect to the apparent 


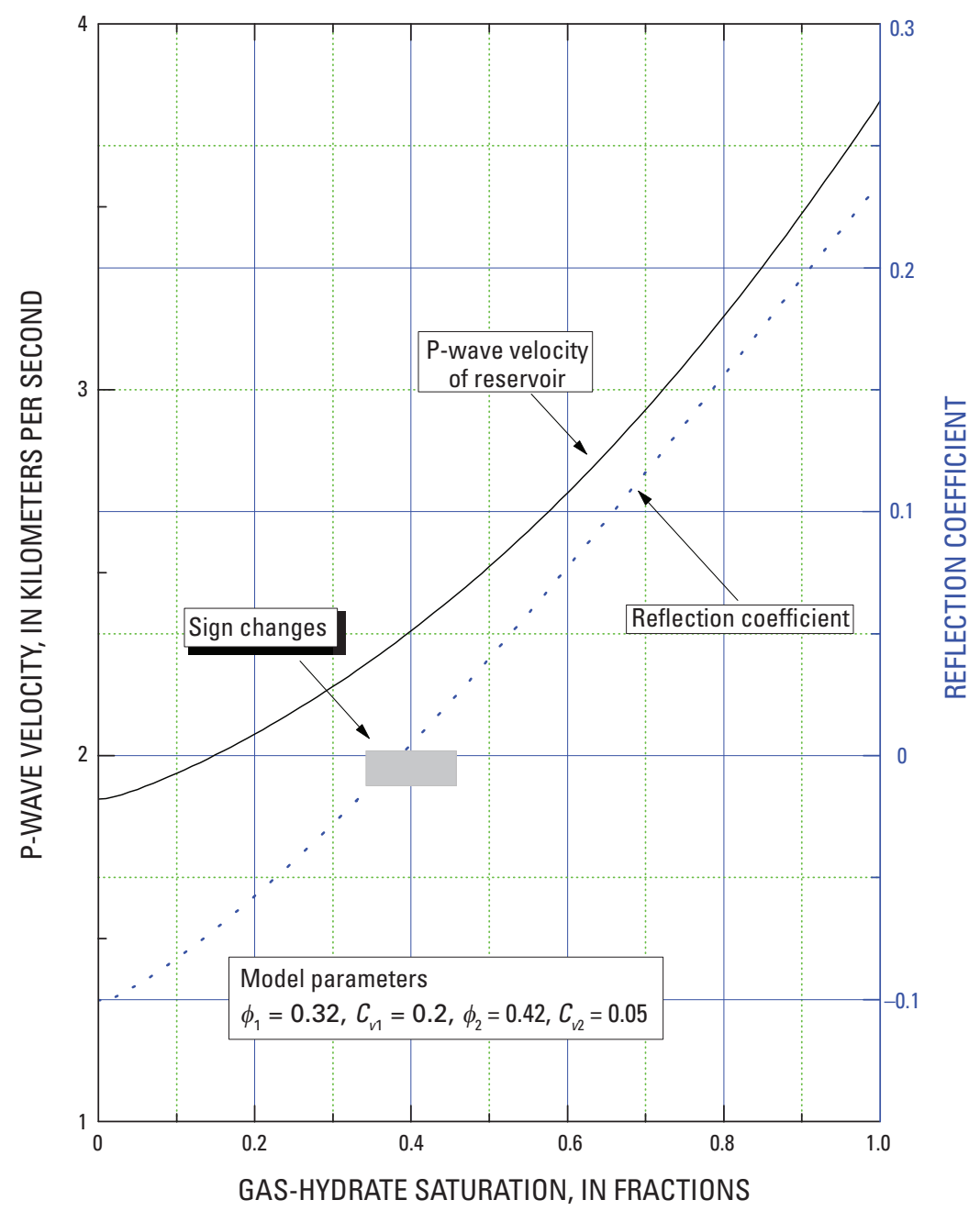

Figure 14. Calculated P-wave velocity and reflection coefficient for the model shown in figure 13. $\phi$, porosity of the seal; $\phi_{2}$, porosity of the reservoir; $C_{v^{\prime}}$ clay volume content of the seal; $C_{v^{\prime}}$ clay volume content of the reservoir.

time thickness (that is, the mapped peak-to-trough time from the seismic section). For a given saturation, the amplitude increases until it reaches tuning thickness and then decreases as the thickness increases further. For a given thickness, the amplitude increases and time thickness decreases as the gashydrate saturation increases. A detailed description of the interpretation procedure is given in Lee and others (in press), and a practical approach is summarized in appendix 3 .

One of the constraints of interpreting the seismic amplitude using the complex thin-bed analysis shown in Lee and others (in press) is that the interpretation depends on the reservoir and seal models. It is important to examine how spatial and depth variations of reservoir and seal properties affect the estimated saturation and thickness of the GHBS. Appendix 2 shows two additional reservoir and seal models derived at depths greater than those shown in figure 13. (Details of the reservoir and seal models are shown in appendix figures 18 and 19.) Two remarkable properties of all the models are that the P-wave velocity of a reservoir without gas hydrate in the pore is less than that of the seal, and the porosity of the reservoir is higher than that of the seal. The difference of porosity between the seal and reservoir is about 10 percent.

Figure 16 shows an example of the interpretation of the saturation and thickness of GHBS using two different reservoir and seal models, the Arco Temptation \#1 and Arco Till \#1 wells (models shown in the appendix 2). Reference amplitude is defined as the amplitude expected from thick GHBS with 40-percent gas-hydrate saturation (untuned amplitude) for a given reservoir and seal properties and input frequency. All amplitudes shown in figure 16 are normalized using this reference amplitude for each model. The open circles in figure $16 \mathrm{~A}$ are arbitrary time-thickness and amplitude pairs to test the effect of different seal and reservoir properties for the interpretation. Figure $16 B$ shows the estimated gas-hydrate saturation using both models. The largest difference in 

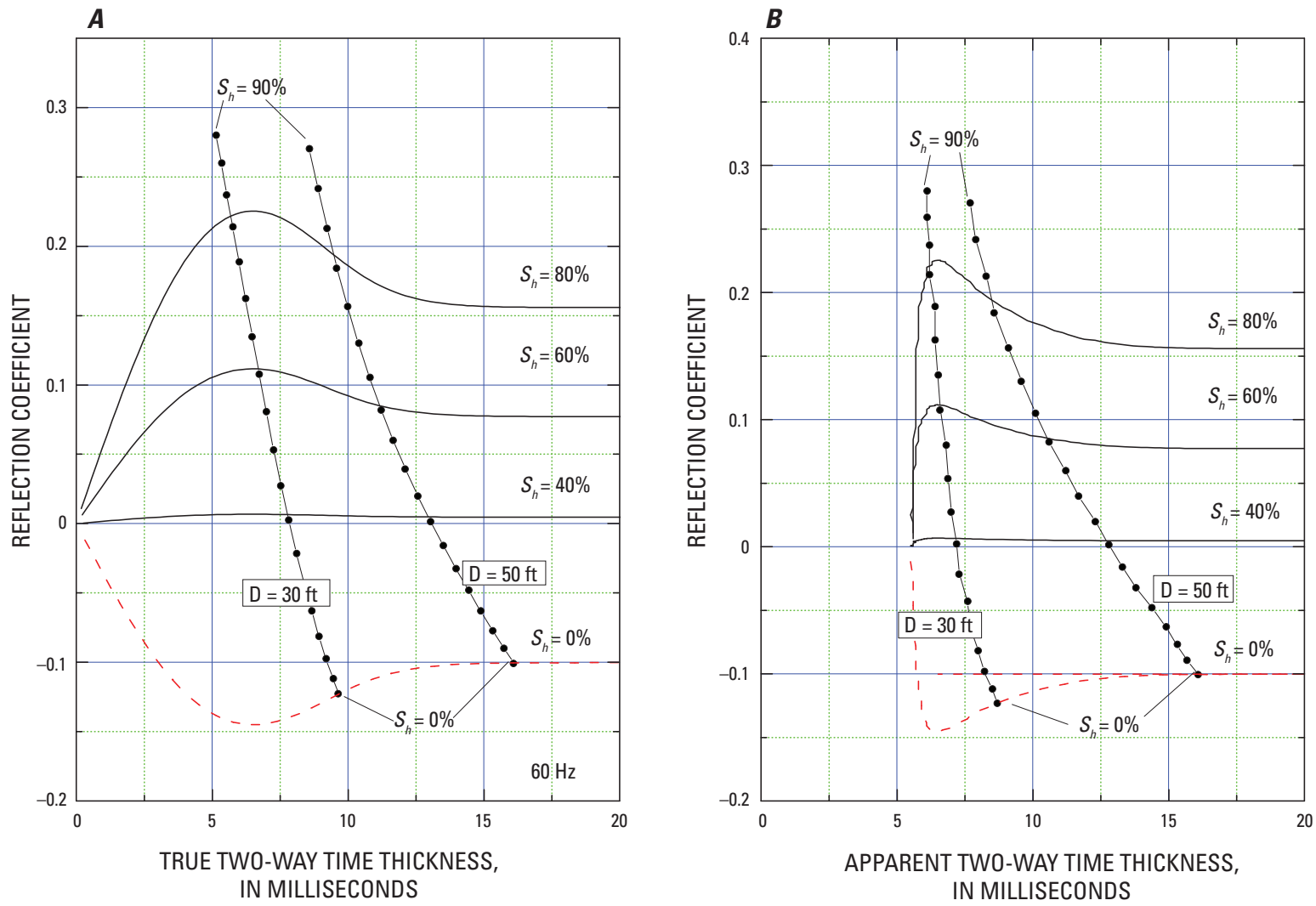

\section{EXPLANATION}

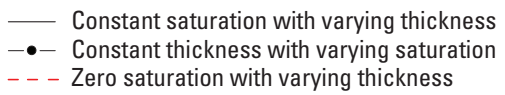

Figure 15. Graph showing relations between reservoir thickness, gas-hydrate saturation, and seismic amplitude using a $60-\mathrm{Hz}$ (hertz) Ricker wavelet. $\boldsymbol{A}$. Relation between true reservoir thickness and amplitude. $S_{h^{\prime}}$ gas-hydrate saturation; $D$, thickness of reservoir. $\boldsymbol{B}$. Relation between apparent two-way time thickness and seismic amplitude.

gas-hydrate saturation between two models is about 4 percent. Figure $16 C$ shows the net pay as a function of two-way time thickness (saturation $\times$ thickness). The largest difference between two models is about $0.5 \mathrm{~m}$. This example illustrates that the gas-hydrate saturation and thickness can be reliably estimated from any of the models shown in this report (models shown in figures 14, 18, and 19). The accurate estimates of gas-hydrate saturation and net pay thickness in the above example come from the fact that the normalized amplitude is used in the interpretation and that the properties of the seal and the reservoir are similar, with a difference in porosity between the reservoir and the seal being about 10 percent. On the basis of well logs and geological consideration, the reservoir and seal properties in the assessment area on ANS do not change significantly from the models shown in this report. However, calculating the normalized amplitude with specified gas-hydrate saturation is a subjective process and requires caution. Judiciously normalized amplitude can be derived using a trial and error method, while incorporating well log information and geology.

\section{Summary and Conclusions}

Because the area of seismic analysis is delineated by the theoretically determined gas-hydrate stability zone (GHSZ), it is important to determine the GHSZ at an early stage in the project. Temperature data and the GHSZ indicate that gas hydrate can coexist with ice inside the permafrost interval. By utilizing the marked difference in the thermal conductivities of ice and gas hydrate, a methodology is developed to distinguish ice from gas hydrate in the commingled zone. At the Husky Oil Atigaru PT \#1 well, a possible gas-hydrate interval commingled with ice at a depth of approximately $800 \mathrm{ft}$ was identified using the methodology, although there was no independent evidence supporting the finding. The theory also indicates that the ability to distinguish gas hydrate from ice in sediment increases as the accuracies of porosity, saturation, and clay volume increase.

Most of the wells had no well log data at shallow depths where most of the GHBS are present. In order to tie well log 


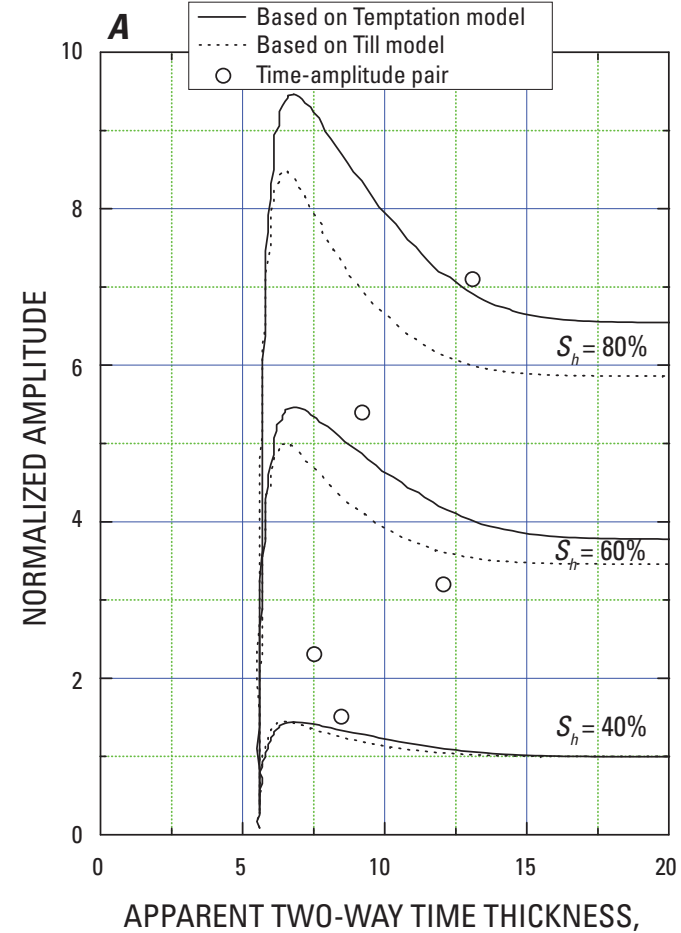

IN MILLISECONDS
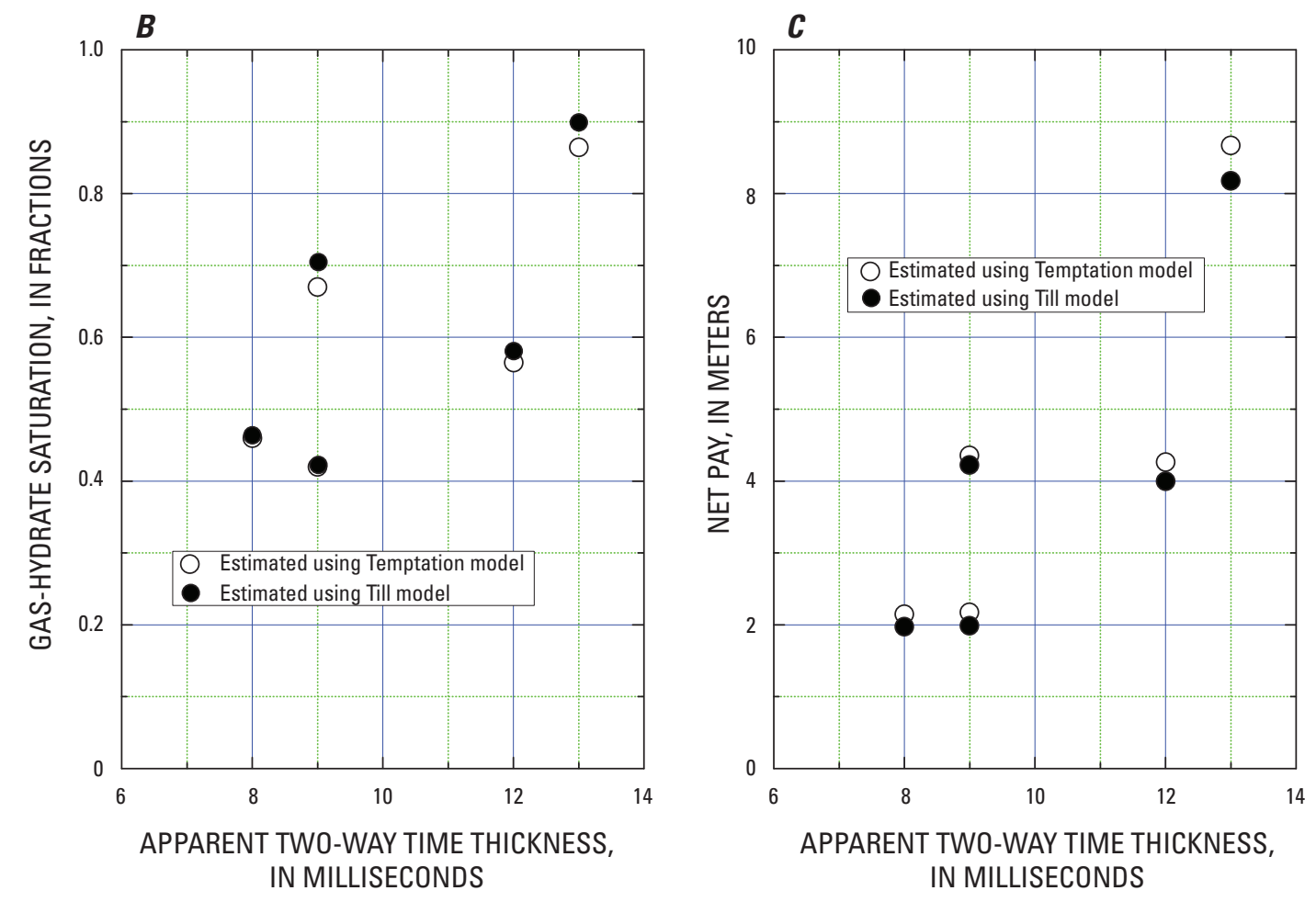

Figure 16. Plots showing various relations between apparent time thickness, amplitude, estimated saturation, and net pay thickness. Temptation, Arco Temptation \#1 well; Till, Arco Till \#1 well. $\boldsymbol{A}$. Relation between apparent time thickness and amplitude. Small circles are simulated normalized amplitude and apparent time pairs. $\boldsymbol{S}_{h^{\prime}}$ gas-hydrate saturation. $\boldsymbol{B}$. Estimated gas-hydrate saturations. $\boldsymbol{C}$. Estimated net pay thickness. 
information to the seismic data, it is essential to generate accurate synthetic seismograms. Due to the lack of shallow well logs, the P-wave velocities were predicted from resistivity logs using various methods. These predicted P-wave velocities were crucial for generating reasonable synthetic seismograms. The method of predicting the velocities by explicitly inserting pore saturations estimated from the resistivity log into an acoustic equation was particularly useful.

Estimating the quantity of in-situ gas hydrate using prospect analysis requires a reasonable seal and reservoir model to quantify the reservoir thickness and gas-hydrate saturations from the mapped seismic amplitude and peak-trough two-way time. Because estimating saturation and thickness depend on a particular reservoir and seal model, and because only observed amplitude and time are input to the complex thin-bed analysis, all interpretations should be assessed to verify whether the identified potential prospect makes sense geologically.

\section{Acknowledgments}

We thank Tanya Inks, IS Interpretation Services, Inc., Denver, Colo., for providing figure 9. Many comments and suggestions by Tanya Inks and Kristen Lewis are very much appreciated.

\section{References Cited}

Collett, T.S., 2000, Quantitative well-log analysis of in-situ natural gas hydrates: Golden, Colorado School of Mines, Ph.D. dissertation, $535 \mathrm{p}$.

Collett, T.S, Bird, K.J., Kvenvolden, K.A., and Magoon, L.B., 1988, Geologic interrelations relative to gas hydrates within the North Slope of Alaska: U.S. Geological Survey OpenFile Report 88-389, 150 p.

Clow, G.D., and Lachenbruch, A.H., 1998, Borehole locations and permafrost depths, Alaska, USA, in International Permafrost Association, Data and Information Working Group, comps., Circumpolar active-layer permafrost system (CAPS): Boulder, University of Colorado, NSIDC, CDROM, version 1.0, available from National Snow and Ice Data Center, nsidc@kryos.colorado.edu.

Dillon, W.P., Lee, M.W., Felhaber, K., and Coleman, D.F., 1993, Gas hydrates on the Atlantic continental margin of the United States-Controls on concentration, in Howell, D.G., ed., The future of energy gases: U. S. Geological Survey Professional Paper 1570, p. 313-330.

Hartmann, Andreas, Rath, V., Clauser, C., 2005, Thermal conductivity from core and well log data: International Journal of Rock Mechanics and Mining Science, v. 42, p. $1,042-1,055$.
Helgerud, M.B., 2001, Wave speeds in gas hydrate and sediments containing gas hydrate-A laboratory and modeling study: Palo Alto, Calif., Stanford University, Ph.D. dissertation, 249 p.

Hill, R., 1952, The elastic behavior of crystalline aggregate: Proceedings of the Physical Society, London, A65, p. 349-354.

Inks, T.L., Lee, M.W., Agena, W.F., Taylor, D.J., Collett, T.S., Hunter, R., and Zyrianova, M., in press, Prospecting for gas hydrate accumulations using 2D and 3D seismic data, Milne Point, North Slope, Alaska, in Collett, T.S., Johnson, Art, Knapp, Camelia, and Boswell, Ray, eds., Natural gas hydrates-Energy resource potential and associated geologic hazards: American Association of Petroleum Geologist Memoir 89 (DVD-ROM).

Judge, A.S., 1973, The prediction of permafrost thickness: Canadian Geotechnical Journal, v. 10, p. 1-11.

Krief, M., Garta, J., Stellingwerff, J., and Ventre, J., 1990, A petrophysical interpretation using the velocities of $\mathrm{P}$ and $\mathrm{S}$ waves (full-waveform sonic): The Log Analyst, v. 31, p. 355-369.

Lachenbruch, A.H., and Brewer, M.C., 1959, Dissipation of the temperature effect of drilling a well in Arctic Alaska: U.S. Geological Survey Bulletin 1083-C, p. 1,515-1,529.

Lachenbruch, A.H., Sass, J.H., Lawver, L.A., Brewer, M.C., Marshall, B.V., Munroe, R.J., Kennelly, J.P., Jr., Galanis, S.P., Jr., and Moses, T.H., Jr., 1988, Temperature and depth of permafrost on the Arctic slope of Alaska, in Gryc, George, ed., Geology and exploration of the National Petroleum Reserve in Alaska, 1974 to 1982: U. S. Geological Survey Professional Paper 1399, p. 645-656.

Lachenbruch, A.H., Sass, J.H., Marshall, B.V., and Moses, T.H., Jr., 1982, Thermal regime of permafrost at Prudhoe Bay, Alaska: U.S. Geological Survey Open-File Report $82-535,77 \mathrm{p}$.

Lee, M.W., 2002, Modified Biot-Gassmann theory for calculating elastic velocities for unconsolidated and consolidated sediments: Marine Geophysical Researches, v. 23 , p. 403-412.

Lee, M.W., 2005, Well log analysis to assist the interpretation of 3-D seismic data at the Milne Point, North Slope of Alaska: U.S. Geological Survey Scientific Investigations Report 2005-5048, 18 p. 


\section{Assessing Gas-Hydrate Prospects on the North Slope of Alaska-Theoretical Considerations}

Lee, M.W., and Collett, T.S., 2005, Assessments of gas hydrate concentrations estimated from sonic logs in the Mallik 5L-38 well, N.W.T., Canada, in Dallimore, S.R., and Collett, T.S., eds., Scientific results from the Mallik 2000 gas hydrate production research well program, Mackenzie Delta, Northwest Territories, Canada: Geological Survey of Canada, Bulletin 585, 10 p.

Lee, M.W., and Collett, T.S., 2008, Integrated analysis of well logs and seismic data at the Keathley Canyon, Gulf of Mexico, for estimation of gas hydrate concentrations: Marine and Petroleum Geology, doi 10.1016/j.marpetgeo.2007.09.002.

Lee, M.W., Collett, T.S., Inks, T.L., in press, Seismic attribute analysis for gas-hydrate and free-gas prospects on the North Slope of Alaska, in Collett, T.S., Johnson, Art, Knapp, Camelia, and Boswell, Ray, eds., Natural gas hydratesEnergy resource potential and associated geologic hazards: American Association of Petroleum Geologist Memoir 89 (DVD-ROM).

Lee, M.W., and Dillon, W.P., 2001, Amplitude blanking related to the pore-filling of gas hydrate in sediments: Marine Geophysical Researches, v. 22, p. 101-109.

Marion, Dominique, Nur, A., Yin, H., and Han, D., 1992, Compressional velocity and porosity in sand-clay mixture: Geophysics, v. 57, p. 554-563.
Osterkamp, T.E., and Payne, M.W., 1981, Estimates of permafrost thickness from well logs in northern Alaska: Cold Regions Science and Technology, v. 5, p. 13-17.

Pratson, L.F., Stroujkova, A., Herrick, D., Boadu, F., and Malin, P., 2003, Predicting seismic velocity and other rock properties from clay content only: Geophysics, v. 68, p. $1,847-1,856$.

Rudman, A.J., Whaley, J.F., Blakely, R.F., and Biggs, M.E., 1975, Transform of resistivity to pseudovelocity logs: American Association of Petroleum Geologists Bulletin, v. 59 , p. $1,151-1,165$.

Ruppel, Carolyn, Von Herzen, R.P., and Bonneville, A., 1995, Heat flux through an old ( 175 Ma) passive margin: Offshore southeastern United States: Journal of Geophysical Research, v. 100 (B10), p. 20,037-20,058.

Sloan, E.D., Jr., and Koh, C.A., 2008, Clathrate hydrates of natural gases: New York, Marcel Dekker, Inc., 721 p.

Western Atlas International, Inc., 1995, Introduction to wireline log analysis: Western Atlas International, Inc., chap. 4, p. 137-184. 


\section{Appendix 1. Modified Biot-Gassmann Theory (BGTL)}

Lee (2002) derived the following shear modulus based on the assumption that $V_{s}=V_{p} G \alpha(1-\phi)^{n}$, where $V_{\mathrm{p}}$ is the $\mathrm{P}$-wave velocity, $V_{s}$ is the S-wave velocity, $\alpha$ is the $V_{s} / V_{\mathrm{p}}$ of the matrix material, and $\phi$ is porosity. $G$ and $n$ are parameters depending on differential pressure, consolidation, and clay content. The shear modulus is given by:

$$
\mu=\frac{\mu_{m a} k_{m a}(1-\beta) G^{2}(1-\phi)^{2 n}+\mu_{m a} \beta^{2} M G^{2}(1-\phi)^{2 n}}{k_{m a}+4 \mu_{m a}\left[1-G^{2}(1-\phi)^{2 n}\right] / 3}
$$

where

and

$$
\frac{1}{\mathrm{M}}=\frac{(\beta-\phi)}{k_{m a}}+\frac{\phi}{k_{f l}}
$$

$k_{m a}, \mu_{m a}, k_{f l}, \phi$, and $\beta$ are the bulk modulus of matrix, the shear modulus of the matrix, the bulk modulus of the fluid, porosity, and the Biot coefficient, respectively.

For the bulk modulus of sediments, the Biot-Gassmann theory gives:

$$
k=k_{m a}(1-\beta)+\beta^{2} M
$$

Elastic velocities of water-saturated sediments can be computed from the elastic moduli by the following formulas:

$$
V_{p}=\sqrt{\frac{k+4 \mu / 3}{\rho}} \text { and } V_{s}=\sqrt{\frac{\mu}{\rho}}
$$

where

$\rho$ is density of the formation given by $\rho=(1-\phi) \rho_{m a}+\phi \rho_{f f}$, where $\rho_{m a}$ and $\rho_{f l}$ are the matrix density, and pore fluid density, respectively.

For soft rocks or unconsolidated sediments, the following Biot coefficient is used (Lee, 2002):

$$
\beta=\frac{-184.05}{1+e^{(\phi+0.56468) / 0.10817}}+0.99494
$$

For hard or consolidated formations, the following formula by Krief and others (1990) is used:

$$
\beta=1-(1-\phi)^{3.8}
$$

The exponent $n$ is given by:

$$
n=\left[10^{\left(0.426-0.235 \log _{10} p\right)}\right] / m,
$$

and

$G$ is given by (Lee, 2005):

$$
G=0.9552+0.0448 e^{-C_{v} / 0.06714}-0.18 \sqrt{S_{h}}
$$

where

$p$ is differential pressure in MPa, $m$ is a constant related to the degree of consolidation, $C_{v}$ is the decimal clay-volume content of the matrix, and $S_{h}$ is the decimal gas-hydrate concentration in the pore space.

Previously, $S_{h}^{2}$ instead of $\sqrt{S_{h}}$ was used in equation 1-7 (Lee, 2005; Lee and Collett, 2005; Lee and others, in press), which is estimated from velocities of GHBS measured at the Mallik well sites, McKenzie Delta, Canada. The new equation provides more accurate velocities of GHBS. For a detailed discussion of parameters $n$ and $G$, consult Lee (2002).

The effect of the gas hydrate on the elastic velocities is modeled such that gas hydrate acts as part of the frame or the skeleton (Helgerud, 2001). The elastic moduli of the composite matrix are computed by Hill's average equation (Hill, 1952).

In order to accommodate various degrees of consolidation and compaction, the following geometric mean of the Biot coefficient is proposed, which is appropriate for sediments that are semiconsolidated (Lee, 2005):

$$
\beta=\beta_{1}^{\delta} \beta_{2}^{1-\delta}
$$

where

$\beta_{1}$ is the Biot coefficient for unconsolidated sediments (equation 1-4), $\beta_{2}$ is the Biot coefficient for consolidated sediments (equation 1-5), and $\delta$ is a weight. When $\delta=1$, the mean Biot coefficient is just the Biot coefficient for unconsolidated sediments. When $\delta=0$, the mean Biot coefficient is that of consolidated sediments. 


\section{Appendix 2. Reservoir and Seal Models}

To investigate the variability of reservoir and seal properties, well logs at two additional ANS wells were analyzed, the Arco Temptation \#1 well and the Arco Till \#1 well. To derive reservoir properties, the intervals that possibly contain gas hydrate in the pores were chosen and analyzed. The criteria for choosing the gas-hydrate reservoir interval are based on (1) high resistivity, (2) high P-wave velocity, (3) high-density porosity, and (4) low gamma ray. An example from the Arco Temptation \#1 well is shown in figure 17A. An interval near 2,200 ft shows high resistivities, high P-wave velocities, low bulk densities (high porosities), and low shale volumes (not shown) compared to the adjacent intervals. Figure $17 B$ shows the P-wave velocity and density porosity with gas-hydrate saturations estimated from the resistivity and P-wave velocity. The gas-hydrate saturations estimated from the resistivity log agree well with those estimated from the P-wave velocity log.

In order to build the reservoir model, the P-wave velocity without gas-hydrate saturation is required. This can be accomplished by accounting for the effect of gas hydrate on the P-wave velocity log by applying the BGTL. Figure $18 A$ shows the density porosity and the P-wave velocity without the effect of gas hydrate, calculated saturation shown in figure 17A, and the BGTL with $m=1.8$. Like the reservoir model at the Arco
Till \#1 well shown in figure 13, calculated $\mathrm{P}$-wave velocities in the reservoir interval are less than $\mathrm{P}$-wave velocities of the seal. Figure $18 B$ shows the measured $\mathrm{P}$-wave velocities along with modeled P-wave velocities predicted from the BGTL with $p=7.5 \mathrm{MPa}, m=1.8, C_{v}=0.12$, and $\delta=0.9$. The average velocity and porosity for the seal and reservoir are shown with a solid star and an open star, respectively. As shown in figure $18 B$, the velocity and porosity for the seal are $2.2 \mathrm{~km} / \mathrm{s}$ and 0.35 percent, respectively, whereas the velocity and porosity for the reservoir without the gas hydrate are $1.9 \mathrm{~km} / \mathrm{s}$ and 0.45 percent.

Another example of a reservoir and seal model from the ANS is shown in figure 19. This model is from the Arco Till \#1 well at the depth of approximately 2,350 ft. The P-wave velocity and porosity for the seal are $2.2 \mathrm{~km} / \mathrm{s}$ and 0.3 percent, respectively, whereas those for the reservoir are $1.97 \mathrm{~km} / \mathrm{s}$ and 0.39 percent. An interesting observation is that the porosity difference between the seal and the reservoir for all three models shown in this report is about 10 percent, and the $\mathrm{P}$-wave velocities of the reservoirs without gas hydrate are less than those of the seals.

The depths of the reservoir models for the Arco Temptation \#1 and Arco Till \#1 shown in this appendix are deeper
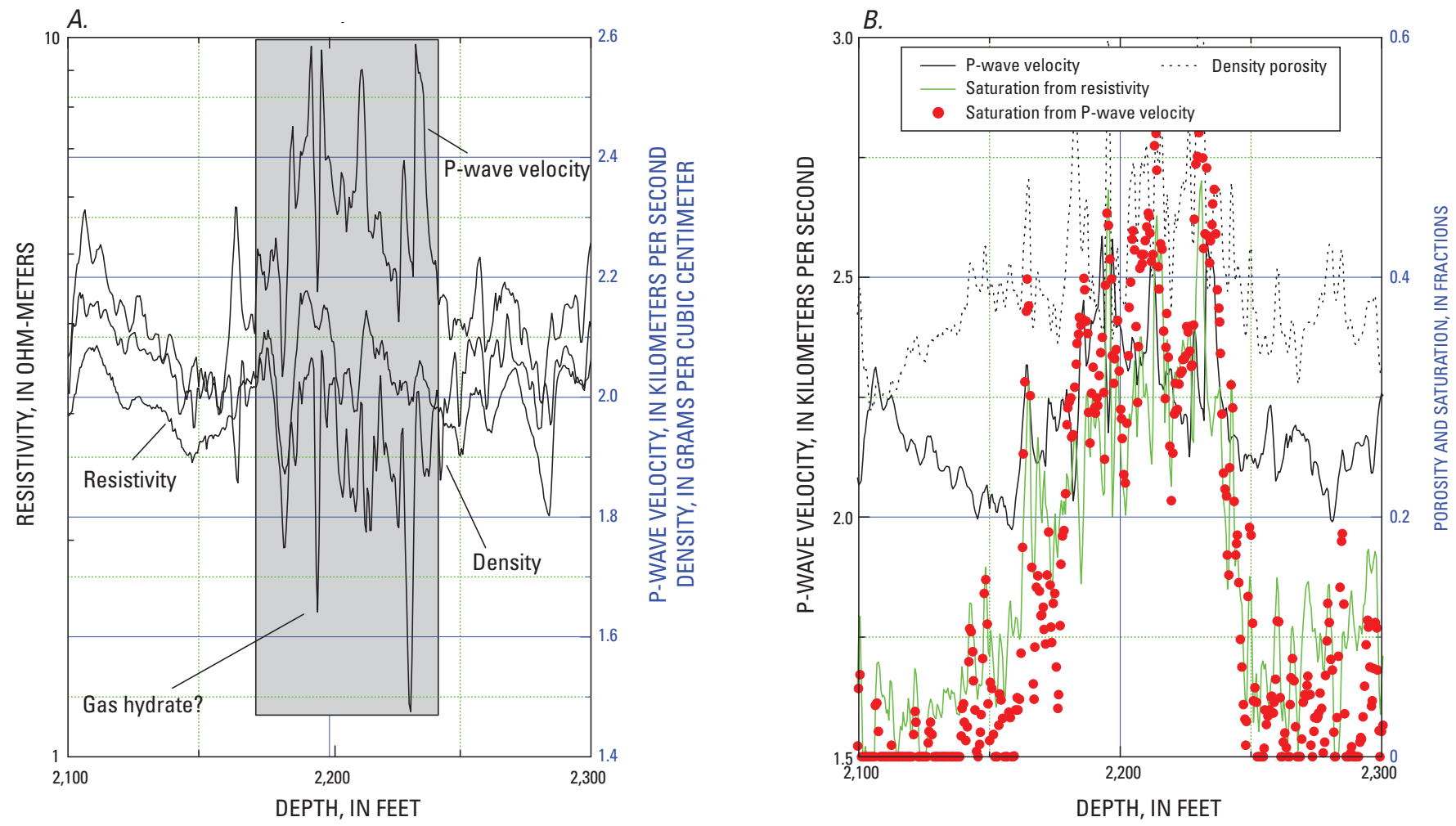

Figure 17. Well log analysis at Arco Temptation \#1 well, Alaska North Slope, to derive reservoir and seal models. A. Measured P-wave velocity, formation resistivity, and bulk density. $\boldsymbol{B}$. Gas-hydrate saturations estimated from P-wave velocity and formation resistivity with density porosity and $\mathrm{P}$-wave velocity. 
than the expected base of the gas-hydrate stability zone. Incorporating mud log responses into the analysis, these reservoirs appear to be oil-sand reservoirs rather than gas-hydrate reservoirs, although it is difficult to differentiate gas hydrate from heavy oil due to the similar velocities of gas-hydrate- and oil-bearing sands. However, when deriving the characteristics of the reservoir model, it is not significant whether to assume that the pore saturant is gas hydrate or heavy oil, because the properties without gas hydrate or heavy oil in the pores are required.
The reservoir and seal properties shown here are very important for interpreting the seismic response of gas-hydratebearing sediment. All models indicate amplitude blanking at certain gas-hydrate saturations and phase reversals are expected as the gas-hydrate saturation increases as shown in figure 13. Gas-hydrate prospects with high gas-hydrate saturation manifest themselves as high-amplitude reflections (bright spots). Bright spots with very low background amplitude and phase reversals are good indicators of potential prospects.
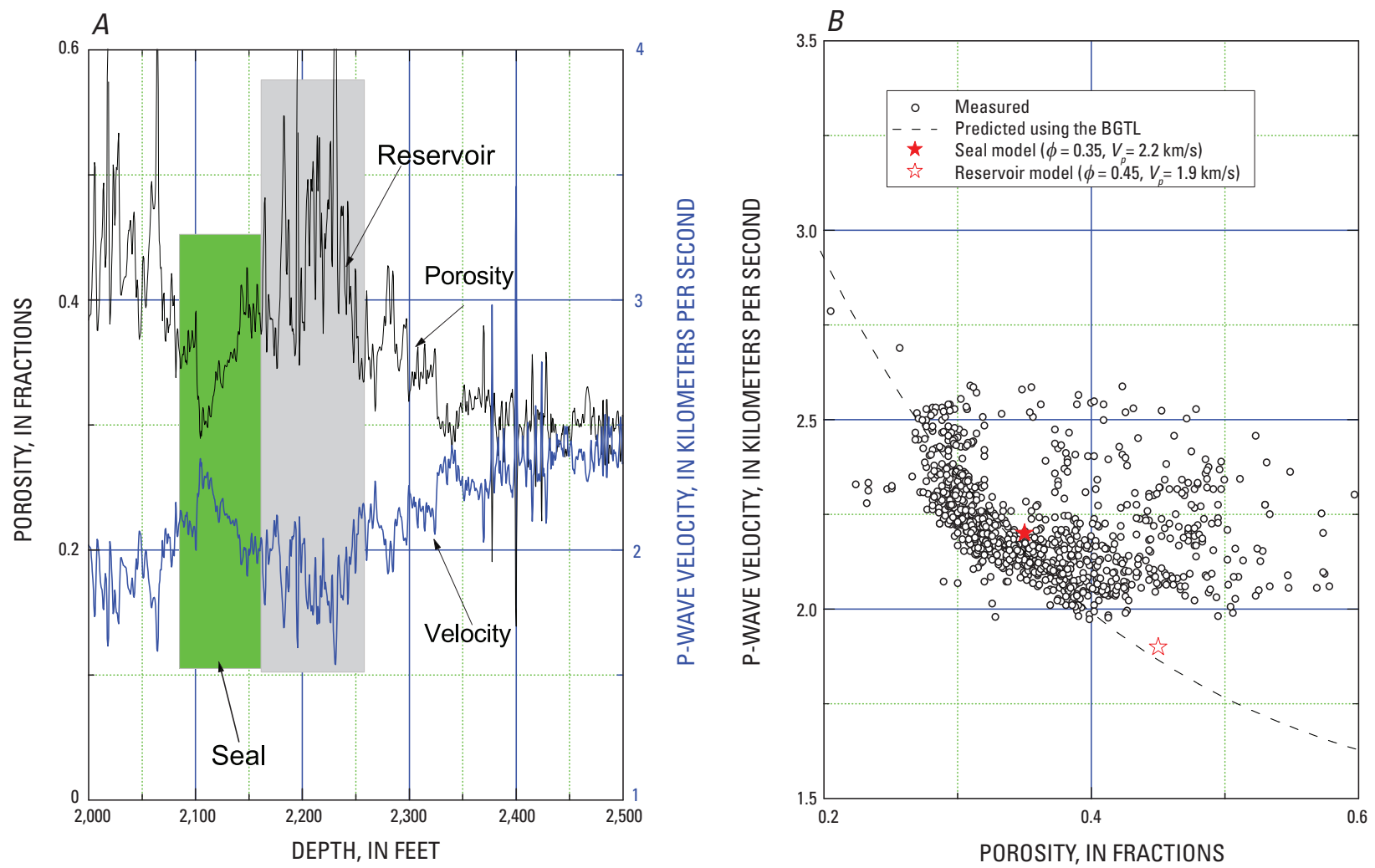

Figure 18. Reservoir and seal models for Arco Temptation \#1 well, Alaska North Slope. A. Density porosity and simulated $\mathrm{P}$-wave velocity, assuming no gas hydrate in the pore. B. Measured P-wave velocity with predicted P-wave velocity using the model parameters shown in the figure. $\phi$, porosity; $V_{p}, \mathrm{P}$-wave velocity; BGTL, modified Biot-Gassmann theory. 

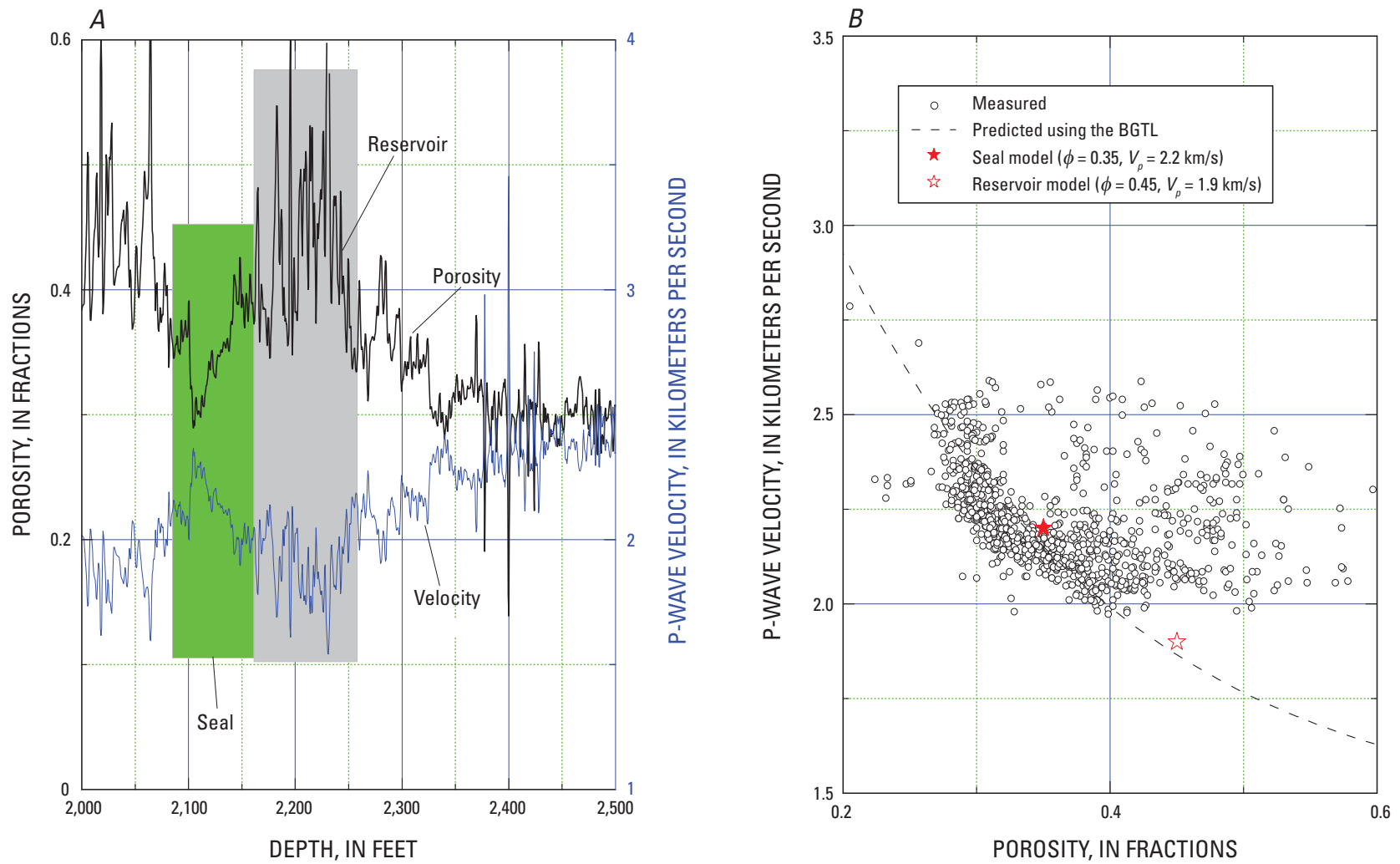

Figure 19. Reservoir and seal models for Arco Till \#1 well, Alaska North Slope. A. Density and simulated P-wave velocity, assuming no gas hydrate in the pore. $\boldsymbol{B}$. Measured $\mathrm{P}$-wave velocity with predicted P-wave velocity using the model parameters shown in the figure. $\phi$, porosity; $V_{p}, \mathrm{P}$-wave velocity; BGTL, modified Biot-Gassmann theory. 


\section{Appendix 3. Saturation and Thickness Interpretation Procedure}

\section{Assumptions}

It is assumed that a peak-trough waveform in a seismic section is a reflection from a gas-hydrate reservoir with zerophase wavelet, and the seismic polarity is preserved throughout the seismic section. It is also assumed that a positive polarity corresponds to a seismic response generated from low to high impedance contrast (pressure connection). Therefore, a peak is a reflection corresponding to the top of the reservoir, a trough is a reflection from the bottom of a reservoir, and the magnitudes of the peak and trough amplitude are the same.

The properties of the reservoir and seal are uniform throughout the analysis area. The amplitude variation with two-way travel time (time thickness) is interpreted in such a way that the reservoir thicknesses and saturations vary according to the theoretical predictions using the reservoir and seal model.

\section{Constraints}

If mapped peak and trough amplitudes are quite different, some of the assumptions are violated, implying that the wavelet is not zero phase or that seal properties on the top and bottom of the reservoir are quite different. If this is true, the estimation has a high degree of uncertainty. In this case different seal and reservoir models or different interpretation methods such as a thick-bed interpretation could be attempted.

\section{Practical Procedures}

1. Calculate the amplitude variation with saturation and thickness based on the Till model shown in figure 14 using a 50-Hz Ricker wavelet or a wavelet with an appropriate measured dominant frequency. The model parameters are: $\phi_{1}=0.32$ and $C_{v}=0.2$ for the seal and $\phi_{2}$ $=0.42$ and $C_{v}=0.05$ for the reservoir. Based on well logs, it is determined that the appropriate BGTL parameters to compute velocities are $m=1.8$, and the differential pressure is calculated from the depth of the prospect assuming normal hydrostatic pressure. Normalize the theoretical amplitudes using the reference amplitude corresponding to 0.45 -gas-hydrate saturation for a thick reservoir (untuned amplitude).
2. Assume that mapped peak amplitudes are reflections associated with gas-hydrate-bearing sediments with saturations varying from 0.4 to 0.9 . Assume small background amplitude (not mapped) are reflections associated with gas-hydrate-bearing sediments with gas-hydrate saturations less than 40 percent. Normalize the mapped amplitude in such a way that a normalized amplitude of 1 represents the reflection from the reservoir saturated with 45-percent gas hydrate.

3. Fit the measured time thickness to the calculated apparent time thickness computed in step 1. For a given time thickness, fit the normalized tuning curve to the normalized mapped amplitude to estimate the gas-hydrate saturation.

4. From the gas-hydrate saturation estimated in step 3, the relation between true and apparent time thickness, and the theoretical prediction of P-wave velocity, the thickness of the reservoir $(d)$ can be calculated by $d=$ (true time) $\times$ (interval velocity)/2. 
Publishing support provided by: Denver Publishing Service Center

For more information concerning this publication, contact: Team Chief Scientist, USGS Central Energy Resources

Box 25046, Mail Stop 939

Denver, CO 80225

(303) 236-1647

Or visit the Central Energy Resources Team site at: http://energy.cr.usgs.gov/ 


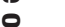

$\frac{9}{31}$

9 Printed on recycled paper 